\title{
Las declaraciones de los Estados y la Convención de las Naciones Unidas sobre el Derecho del Mar de 1982. Su aplicación al sistema de solución de controversias en el asunto del Mar del Sur de China (Filipinas v. China)
}

\section{States' Unilateral Staments and the United Nations Convention on the Law of the Sea 1982. Its Application in the Dispute Settlement System in the South China Sea Case (Philippines v. China)}

Les déclarations des États et la Convention des Nations Unies sur le Droit de la Mer de 1982. Son application au système de règlement des différends dans l'affaire de la Mer de Chine Méridionale (Philippines c. Chine)

Leopoldo M. A. Godio*

Sumario: I. Introducción. Concepto y naturaleza de las declaraciones. II. Las declaraciones de los Estados y la Convención de Viena sobre el Derecho de los Tratados. III. La contribución de la Comisión de Derecho Internacional y la Guía de la Práctica sobre las Reservas a los Tratados. IV. La contribución de los tribunales internacionales al estudio de las declaraciones interpretativas en general. V. Tipos de declaraciones autorizadas en la Convención de las Naciones Unidas sobre el Derecho del Mar. Examen de los artículos 287, 298 y 310. VI. Conclusión. VII. Bibliografía.

* Abogado y magister en relaciones internacionales (UBA). Miembro titular de la AADI; miembro del Instituto de Derecho Internacional del CARI; investigador adscripto en el Instituto de Investigaciones Jurídicas y Sociales “Ambrosio L. Gioja”; miembro del Instituto de Derecho Internacional de la Academia Nacional de Derecho. E-mail: leopoldogodio@derecho.uba.ar.

Artículo recibido el 6 de enero de 2017 Aprobado para publicación el 25 de septiembre de 2017 
RESUMEN: El presente trabajo analiza el uso de las declaraciones interpretativas y sus actuales desafíos, con especial énfasis en la situación que presentan los artículos 287, 298, 309 y 310 de la Convención de las Naciones Unidas sobre el Derecho del Mar de 1982 a la luz del caso reciente y no por ello menos polémico: la controversia entre Filipinas y China en el área del Mar del Sur de China.

Palabras clave: tratados, declaraciones interpretativas, solución de controversias, límites, actividades militares.

ABSTRACT: This work analyzes the use of interpretative declarations and the challenges they currently present, with special interest in the situation framed by articles 287, 298, 309 and 310 of the 1982 United Nations Convention on the Law of the Sea, taking into account a recent but not less controversial case: the dispute between the Philippines and China in the area of the South China Sea.

Key words: treaties, interpretative declaration, settlement of disputes, limits, military activities.

RÉSUMÉ: Cet article analyse l'utilisation des déclarations interprétatives et leurs défis actuels, en mettant particulièrement l'accent sur l'application des articles 287, 298, 309 et 310 de la Convention des Nations Unies sur le Droit de la Mer de 1982 dans une affaire récente et très controversée: le différend entre les Philippines et la Chine dans la région de la Mer de Chine du Sud.

Mots-clés: traités, déclarations interprétatives, règlement des différends, limites, activités militaires. 
Esta revista forma parte del acervo de la Biblioteca Jurídica Virtual del Instituto de Investigaciones Jurídicas de la UNAM

\section{INTRODUCCIÓN. CONCEPTO Y NATURALEZA DE LAS DECLARACIONES}

El derecho internacional público se caracteriza, entre otros elementos, por ser un sistema descentralizado y de cuasisubordinación, en el que las relaciones de sus sujetos más representativos se manifiestan, formalmente, a través de tratados, cuyas disposiciones habilitan distintas interpretaciones por parte de los Estados. Éstas han adquirido, en últimas fechas, mayor complejidad y preparación. ${ }^{1}$

En ese sentido, el interés de estos sujetos originarios del derecho internacional se materializa a través de declaraciones - entendidas como una expresión de voluntad, intención u opinión, de modo unilateral y con carácter oficial, aunque es posible que forme parte de una negociación bilateral o multilateral con el propósito de fomentar una intencionalidad o posición grupal ${ }^{2}$ formuladas al momento de prestar su consentimiento en obligar$\mathrm{se}^{3}$ con el objeto de salvaguardar o intentar garantizar una posición de sus opiniones e intenciones oficiales, aclarando enfoques comunes en un contexto multilateral, o bien plantear un enfoque propio con una finalidad estratégica con antelación a la cristalización formal del tratado. Su efecto vinculante constituye, doctrinalmente, una cuestión debatida.

A pesar de su vital importancia en la dinámica contractual-internacional, ${ }^{4}$ las declaraciones interpretativas no han sido en sí mismas uno de los temas

1 Devidal, Pierrick, "Reservations, Human Rights Treaties in the 21st Century: From Universality to Integrity”, LLM Theses and Essays - University of Georgia School of Law, Paper 10, 2003, disponible en: http://digitalcommons.law.uga.edu/stu_llm/10 (fecha de consulta: 31 de octubre de 2016).

2 Dörr, Oliver, “Declaration”, en Wolfrum, Rüdiger (ed.), The Max Planck Encyclopedia of Public International Law, Oxford, Oxford University Press, 2012, para. 1, disponible en: http: / / www.mpepil.com (fecha de consulta: 31 de octubre de 2016).

3 Moncayo, Guillermo R. et al., Derecho internacional público, 3a. reimp., Buenos Aires, Zavalía, 1990, t. I, p. 118.

4 La práctica de esas declaraciones resulta simultánea a la aparición de los tratados multilaterales y se recuerda al respecto, con frecuencia, el Acta Final del Congreso de Viena de 1815, que propició la declaración interpretativa de Gran Bretaña referida al artículo VIII del Tratado de Alianza con Austria, Prusia y Rusia, con el objeto de invitar a Francia y conformar la llamada Pentarquía. La declaración en cuestión aclaraba que las acciones en contra del poder de Napoleón Bonaparte no obligaban a su majestad británica a proseguir acciones armadas 
Esta revista forma parte del acervo de la Biblioteca Jurídica Virtual del Instituto de Investigaciones Jurídicas de la UNAM http://www.juridicas.unam.mx/ https://biblio.juridicas.unam.mx/bjv

https://revistas.juridicas.unam.mx/

DOI: http://dx.doi.org/10.22201/iij.24487872e.2018.18.12098

más destacados en las controversias internacionales, aunque revisten trascendental importancia por los posibles efectos que pueden generar en las relaciones entre Estados parte de un tratado bilateral, ${ }^{5}$ regional o multilateral, que con el tiempo pueden, hipotéticamente y según las características del caso, crear precedentes que culminen en una opinio iuris sive necessitatis respecto de otros Estados y ser recogidas por organismos internacionales en los que éstos formen parte. ${ }^{6}$

Por otro lado, si bien es indiscutible que las resoluciones de la Asamblea General no poseen carácter obligatorio, puede ocurrir que en determinadas condiciones aquéllas produzcan efectos en la formación del derecho internacional mediante la costumbre como fuente. ${ }^{7}$ En otras palabras, parte de la

con miras a imponer en Francia un determinado gobierno, al expresar que “...understood as binding the Contracting Parties... to a commmon effort against the power of Napoleon Buonaparte... but is not to be understood as binding his Britannic Majesty to prosecute the War, with a view of imposing upon France any particular Government”.

5 Respecto a los acuerdos bilaterales, Cameron señala que las declaraciones interpretativas "formalmente" aceptadas por la otra parte transforman a la interpretación en "auténtica". Cfr. Cameron, Iain, “Treaties, Declarations of Interpretation”, en Wolfrum, Rüdiger (ed.), The Max Planck Encyclopedia of Public International Law, Oxford, Oxford University Press, 2012, para. 1, disponible en: http://www.mpepil.com (fecha de consulta: 31 de octubre de 2016).

6 Diez de Velasco Vallejo, Manuel, Instituciones de derecho internacional público, 18a. ed., Madrid, Tecnos, 2013, p. 140. Esta idea se encuentra dentro de los llamados "nuevos procedimientos de codificación” desarrollados, en general, mediante una primera etapa en el marco de una comisión de la Asamblea General — compuesta por representantes de los gobiernosy una segunda que finaliza, en el mejor de los casos, con una resolución de la propia Asamblea General que contenga el texto de una convención, o bien en un llamado a una conferencia diplomática. Sin embargo, en ocasiones se presenta "una fase intermedia, pero a veces única... la adopción de Resoluciones de la A.G. que contienen declaraciones de principios que posteriormente — aunque no siempre - se incluyen y precisan en una convención. Así ha ocurrido, por ejemplo, con la codificación del Derecho del espacio, que ha sido competencia de una comisión ad hoc de la A.G.” (ibidem, p. 143). Al respecto, De la Guardia señala la existencia de una "nueva costumbre" tendiente a "aprobar las convenciones multilaterales por consenso, sobre la base del compromiso o compromisos alcanzados por los contratantes, lo cual no admite la posibilidad de reservas, aunque sí de declaraciones interpretativas". Cfr. Guardia, Ernesto de la, Derecho de los tratados internacionales, Buenos Aires, Ábaco de Rodolfo de Palma, 1997, p. 186 (el destacado pertenece al original).

7 Incluso, algunas de ellas han constituido un hito en la historia del derecho internacional, como la Declaración Universal de los Derechos Humanos (1948) o la Declaración de los principios que regulan los fondos marinos y oceánicos y su subsuelo fuera de los límites de la jurisdicción nacional, dispuesta en la Resolución 2749 de la Asamblea General (disponible en: http: / / www.un.org/es/comun/docs/?symbol=A/RES/2749(XXV) [fecha de consulta: 31 de octu- 
Esta revista forma parte del acervo de la Biblioteca Jurídica Virtual del Instituto de Investigaciones Jurídicas de la UNAM

doctrina reconoce esta posibilidad, de tal manera que una serie de declaraciones desarrollen o precisen algunos de los grandes principios del derecho internacional, de modo que, con el tiempo, se cristalicen como una norma consuetudinaria en vías de formación (in statu nascendi), ya sea por la unanimidad en su adopción, o bien por su origen y práctica posterior (efecto constitutivo) análogo a un convenio innovador. ${ }^{8}$

De hecho, su habitual utilización contiene elementos políticos, económicos o jurídicos en distintos tipos de acuerdos internacionales, sin importar la materia que traten. ${ }^{9}$ Así, por ejemplo, se recurre a ellas en tratados o cláusulas sobre aceptación de jurisdicción obligatoria ${ }^{10} \mathrm{o}$ acuerdos de libre comercio, a fin de aclarar especificaciones sobre las listas de productos. Asimismo, entre los usos más frecuentes de las declaraciones podemos referir a la práctica del "reconocimiento", realizado por los Estados con el objeto de intentar constatar o legitimar la existencia de un hecho, situación o pretensión, como el reconocimiento de un gobierno o la declaración de una guerra, por mencionar algunos. También es posible, aunque menos usual por la gravedad que trae aparejada, la "renuncia" y el "desistimiento".

A pesar de lo anterior, la naturaleza jurídica de las declaraciones encuadra, con razón, dentro de la doctrina de los actos unilaterales del Estado, ${ }^{12}$ ya que sólo es necesario de una manifestación inequívoca que exprese la vo-

bre de 2016]). Para un análisis en detalle, véanse también Barberis, Julio A., Fuentes del derecho internacional, La Plata, Platense, 1973; Barberis, Julio A., Formación del derecho internacional, Buenos Aires, Ábaco de Rodolfo Depalma, 1994.

8 Diez de Velasco Vallejo, Manuel, op. cit., p. 149. El autor refiere, por ejemplo, al caso de la Resolución 2625 (XXV), del 24 de octubre de 1970, que contiene la Declaración de los principios de derecho internacional relativos a las relaciones de amistad y cooperación entre los Estados; la Resolución 1962 (XVIII), del 13 de diciembre de 1963, sobre los principios jurídicos que deben regir la actividad de los Estados en la exploración y utilización del espacio ultraterrestre, adoptada por unanimidad, y la Resolución 2625 (XV), del 14 de diciembre de 1960, adoptada sin votos en contra, referida a la concesión de independencia a los países y pueblos coloniales, confirmada por la práctica anterior. Idem.

9 La República Argentina ha formulado, en la práctica, declaraciones consideradas "políticas” en la Convención sobre la Unión Panamericana (1928) y el protocolo de Buenos Aires que reformó la Carta de la OEA (1967). Cfr. Guardia, Ernesto de la, op. cit., p. 188, nota 83.

10 Fisheries Jurisdiction (Spain v. Canada), Jurisdiction of the Court, Judgment, ICJ Reports 1998, p. 432.

11 Diez de Velasco Vallejo, Manuel, op. cit., p. 155.

12 Nuclear Tests (New Zealand v. France), Judgment, ICJ Reports 1974, pp. 472 y 473, paras. 46 y 49; Nuclear Tests (Australia v. France), Judgment, ICJ Reports 1974, pp. 267 y 268, paras. 43 y 46. 
Esta revista forma parte del acervo de la Biblioteca Jurídica Virtual del Instituto de Investigaciones Jurídicas de la UNAM

luntad de este sujeto, ${ }^{13}$ emanada de un órgano o autoridad con competencia o facultad para obligarle, ${ }^{14}$ que, en principio, no depende de otros actos jurídicos para su validez ni puede considerársele per se lícita y eficaz, puesto que las mismas no pueden prevalecer sobre las disposiciones dispuestas en un tratado. ${ }^{15}$ El acto sólo es vinculante para quien lo formule, salvo que exprese condiciones que aún no se hayan cumplido, con las excepciones o limitaciones que impone el principio pacta terttis. ${ }^{16}$ El efecto de la declaración y su oponibilidad es, según Diez de Velasco Vallejo, una consecuencia del instituto del estoppel, que considera, recordando una sentencia inglesa de 1837, lo siguiente:

Cuando una persona, con sus palabras o con su conducta, produce voluntariamente a otra la creencia de la existencia de un determinado estado de cosas y la induce a actuar de manera que altere su previa posición jurídica, el primero no puede alegar frente al segundo que en realidad existía un estado de cosas diferente. ${ }^{17}$

Este jurista concluye que la institución del estoppel no permite explicar la totalidad de los efectos de los actos unilaterales y el comportamiento de los Estados, aunque sí puede exponer y fundamentar todos esos efectos el principio de la buena fe. ${ }^{18}$ De todos modos, independientemente del carácter político o no de la declaración, sus consecuencias jurídicas siempre están presentes y algunas de ellas, por más "políticamente pura" que parezca su intención, poseen la finalidad de alterar una situación jurídica determinada;

13 Así lo sostuvo la Corte Internacional de Justicia (en adelante "CIJ" o "la Corte", indistintamente) en el asunto entre Burkina Faso y Mali. Cfr. Frontier Dispute, Judgment, ICJ Reports 1986, p. 573, para. 39.

14 ILC, "Guiding Principles Applicable to Unilateral Declarations of States Capable of Creating Legal Obligations, with Commentaries Thereto”, Yearbook of the International Law Commission 2006, vol. II, Part Two (Doc. A/61/10), 2006, pp. 369-381, disponible en: http:// legal.un.org/ilc/texts/instruments/english/commentaries/9_9_2006.pdf (fecha de consulta: 28 de octubre de 2016).

15 Case of the S. S. “Wimbledon”, P.CIJ, Judgment of 17 August 1923 (Serie A, núm. 1), p. 29.

16 Sir Gerald Fitzmaurice, en su quinto informe presentado a la CDI, del 21 de marzo de 1960, sostuvo que se trata, incluso, de cuasiexcepciones. Cfr. ILC, "Law of Treaties. Fifth Report by Sir Gerald Fitzmaurice, Special Rapporteur”, Yearbook of the International Law Commission 1960, vol. II, 1960, pp. 72 y 73.

17 El autor agrega que su configuración no es uniforme, aunque con posterioridad adopta una concepción restrictiva. Cfr. Diez de Velasco Vallejo, Manuel, op. cit., p. 152.

18 Ibidem, p. 153. 
Esta revista forma parte del acervo de la Biblioteca Jurídica Virtual del Instituto de Investigaciones Jurídicas de la UNAM

por ejemplo, el establecimiento de un bloqueo naval o la declaración como persona non grata de un funcionario extranjero, entre otras. ${ }^{19}$

Si bien las "declaraciones" se diferencian de las "declaraciones interpretativas", a pesar de tratarse ambas, en esencia, de actos unilaterales, lo cierto es que los Estados suelen recurrir ampliamente y con habitualidad a las primeras para, por ejemplo, reconocer a un gobierno o atribuirse un comunicado, entre otros.

\section{LAS DECLARACIONES DE LOS ESTADOS Y LA CONVENCIÓN DE VIENA SOBRE El DeRECHO DE LOSTRATAdos}

El "silencio" de la Convención de Viena sobre el Derecho de los Tratados de 1969 a la definición de las declaraciones interpretativas obedece, según De la Guardia, a una resolución de exclusión por parte del Comité de Redacción, sin perjuicio de haberse analizado, oportunamente, la cuestión durante la conferencia. En efecto, en el comentario a la definición de "reserva", la Comisión de Derecho Internacional (CDI) señaló que los Estados,

...al firmar, ratificar, aceptar, aprobar un tratado o adherirse a él, suelen formular declaraciones acerca de cómo entienden algunos asuntos sobre su interpretación de determinadas disposiciones. Tal declaración puede ser una mera aclaración de la actitud del Estado o puede ser equivalente a una reserva, según modifique o no la aplicación de las cláusulas del tratado ya aprobado o la excluya. ${ }^{20}$

De la Guardia considera que las declaraciones interpretativas establecen el sentido que debe poseer el tratado o la norma en un modo determinado y las define, entonces, como

....un acto unilateral, que tiene por objeto hacer una interpretación total o parcial de un tratado, y que ni debe ser confundido con una reserva... su objeto no es excluir la apli-

19 Dörr, Oliver, op. cit., paras. 8-10.

20 Guardia, Ernesto de la, op. cit., p. 187. En efecto, el autor afirma que Waldock las excluyó “...por la simple razón de que esas declaraciones no eran reservas y parecían estar más relacionadas con la interpretación que con la conclusión de los tratados... el significado jurídico de una declaración interpretativa depende siempre de las circunstancias particulares en las cuales es formulada..." (la omisión pertenece al original). Idem. 
Esta revista forma parte del acervo de la Biblioteca Jurídica Virtual del Instituto de Investigaciones Jurídicas de la UNAM http://www.juridicas.unam.mx/ https://biblio.juridicas.unam.mx/bjv https://revistas.juridicas.unam.mx/ DOI: http://dx.doi.org/10.22201/iij.24487872e.2018.18.12098

cación de una disposición del tratado o modificar sus efectos jurídicos, sino solamente atribuir una interpretación determinada en un campo de posibilidades varias de interpretación. ${ }^{21}$

De este modo, aparece inevitable reconocer el problema de la "real" naturaleza de las declaraciones interpretativas y su distinción respecto de las reservas. Al respecto, Fitzmaurice reconoce la dificultad que presentan en algunos casos, considerando a las últimas como aquellas que los Estados incorporan con el objeto de explicar y establecer su percepción respecto de las obligaciones previstas en el tratado; no obstante, aclara que si las declaraciones intentan modificar el alcance o los efectos de la obligación, serán consideradas como reservas. ${ }^{22}$ Esta preocupación es también compartida por Cameron, para quien las declaraciones interpretativas pueden tener una apariencia de reserva, debido a que son unilaterales y suelen presentarse en el momento de la firma, celebración, aprobación, ratificación, depósito o adhesión de un tratado. ${ }^{23}$

Por su parte, Diez de Velasco Vallejo sostiene que son "declaraciones interpretativas" aquellas que los Estados formulan para aceptar determinas

${ }^{21}$ Ibidem, pp. 187-189 (el destacado pertenece al original). Coincidimos con De la Guardia, al considerar que una declaración interpretativa —al igual que una reserva - es, sin duda, una declaración unilateral. Respecto del concepto de unilateral, se sugiere recordar las consideraciones de la CIJ en los asuntos sobre los Ensayos Nucleares, decididos en 1974 y que involucraron, en procesos separados, a Nueva Zelanda y Australia contra Francia. Cfr. Nuclear Tests (New Zealand v. France), Judgment, ICJ Reports 1974, p. 457; Nuclear Tests (Australia v. France), Judgment, ICJ Reports 1974, p. 253.

22 Fitzmaurice, Malgosia, “Treaties”, en Wolfrum, Rüdiger (ed.), The Max Planck Encyclopedia of Public International Law, Oxford, Oxford University Press, 2012, para. 62, disponible en: http://www.mpepil.com (fecha de consulta: 1o. de noviembre de 2016). En idéntico sentido, Waldock, citado por De la Guardia, consideró que "si con la declaración no se persigue alterar los efectos jurídicos de ninguna de las disposiciones del tratado en su aplicación al Estado que la hace, se tratará de una declaración interpretativa que se regirá por las normas sobre interpretación”. Cfr. Guardia, Ernesto de la, op. cit., p. 189.

23 Cameron, Iain, op. cit., paras. 1 y 2. Sin embargo, cabe señalar que este último aspecto resulta materialmente cuestionable, por ejemplo, en la Declaración conjunta de cooperación sobre actividades costa afuera en el Atlántico Sudoccidental entre la República Argentina y el Reino Unido de Gran Bretaña e Irlanda del Norte, firmada el 27 de septiembre de 1995, en la que el Reino Unido presentó una declaración interpretativa al día siguiente de la firma y la República Argentina realizó la propia un día después que su cocontratante. El acuerdo se encuentra extinguido por denuncia argentina del 27 de marzo de 2007. 
Esta revista forma parte del acervo de la Biblioteca Jurídica Virtual del Instituto de Investigaciones Jurídicas de la UNAM

condiciones dentro de límites o modalidades preestablecidas, a fin de atribuirlas en un sentido determinado y no a otro. Sin embargo, el autor posee una interpretación amplia de "reserva" a partir de la definición dispuesta en el artículo 2o., párrafo 1, inciso d, de la Convención de Viena sobre el Derecho de los Tratados de 1969, que comprende a una reserva como "una declaración unilateral, cualquiera que sea su enunciado o denominación...”, que se enrola, en otras palabras, en una tesis no formalista que considera irrelevante la "denominación" y destaca, en cambio, los efectos del acto unilateral, ${ }^{24}$ de modo que las intenciones de los Estados priman sobre la terminología utilizada para expresarlas.

En consecuencia, no resulta adecuado situar a las reservas y las declaraciones como opuestos extremos, y menos aún considerar a las declaraciones interpretativas como una posición intermedia. Así las cosas, es necesario prescindir de los nominalismos e interesarse, en cambio, por el contenido mismo de las afirmaciones y su efecto, primando el fondo sobre la forma, de modo que el rótulo de las declaraciones pase a un segundo plano y dedicarse a sus verdaderas intenciones. La gravedad de estas inquietudes fueron recogidas en la Sexta Comisión de la Asamblea General de la ONU, que, posteriormente, sirvió de inicio para la labor de la $\mathrm{CDI}^{25}$ y el enfoque propuesto por Alain Pellet, en 1993, que apuntó a aceptar que ambos conceptos, reserva y declaración interpretativa, son diferentes y no poseen una relación género-especie. ${ }^{26}$

En nuestra opinión, entendemos que algunas declaraciones no pueden ser consideradas estrictamente reservas — y menos aún presumirlas como tales_- ya que no buscan modificar o excluir los efectos jurídicos de un tratado o parte de sus disposiciones, sino manifestar la elección de opciones previstas expresamente en el acuerdo, o bien realizar aclaraciones sobre el significado de términos no definidos convencionalmente. ${ }^{27}$ Por supuesto, se trata de una tesis que requiere analizar concretamente las declaraciones realizadas — por ejemplo, a través de las reglas generales de interpretación dispuestas en el artículo 31, párrafo 2, inciso b, de la Convención de Viena

24 Diez de Velasco Vallejo, Manuel, op. cit., p. 169.

25 Resolución AG 48/31 y 49/51.

26 Cameron, Iain, op. cit., para. 3.

27 Por ejemplo, no es lo mismo el término "responsabilidad" o "responsibility" para el jurista argentino y el estadounidense, ya que el segundo diferencia, según el caso, la situación de "liability". 
Esta revista forma parte del acervo de la Biblioteca Jurídica Virtual del Instituto de Investigaciones Jurídicas de la UNAM

sobre el Derecho de los Tratados de 1969_- a fin de que las mismas no resulten, según la intención del autor, una reserva tendiente a modificar o excluir los efectos jurídicos del acuerdo. ${ }^{28}$

En relación con la intención, cabe destacar que si bien los Estados no suelen hacer depender su participación en un tratado con arreglo a una declaración interpretada en un sentido — es decir, condicional—-, su hipótesis es posible siempre que la convención en cuestión no prohíba este tipo de fórmulas ${ }^{29}$ tendientes a producir o circunscribir un marco legal respecto a las demás partes, sin que sea, en sentido estricto, una reserva y ni siquiera una declaración interpretativa. Ello, toda vez que no se trata, simplemente, de preferir un punto de vista o una exégesis particular, sino a un interés, un agregado: el Estado que la formula no desea que su posición sea descartada o rechazada ${ }^{30} \mathrm{y}$, por ello, la condiciona como parte del consentimiento en obligarse.

Cameron justifica la existencia de declaraciones interpretativas y su aumento en la práctica reciente: el carácter heterogéneo de los Estados que participan en las conferencias multilaterales, especialmente en aquellas conferencias donde prima el consenso como método de negociación, cuyo "producto" es presentado como un paquete de compromisos y provisiones ambiguas y que, en algunos casos, se explica en consideraciones generadas en instancias parlamentarias mediante el proceso de ratificación de tratados en el ámbito doméstico. ${ }^{31}$

La finalidad de las declaraciones interpretativas puede consistir en: a) una mera información a las otras partes del tratado, que exprese una posición del declarante, $\mathrm{y} b$ ) influir en la futura interpretación del tratado o los órganos creados para su interpretación o solución de controversias. ${ }^{32}$

28 Este último aspecto, que analizaremos más adelante, fue tratado por la CDI en su Guía de la Práctica sobre las Reservas a los Tratados, con el jurista francés Alain Pellet como relator especial. Cfr. CDI, Informe de la Comisión de Derecho Internacional, 63o. periodo de sesiones, 26 de abril-3 de junio de 2011 y 4 de julio-12 de agosto de 2011, Nueva York, Naciones Unidas, 2011 (A/66/10/Add.1).

29 CDI, Informe de la Comisión de Derecho Internacional, 55o. periodo de sesiones, Octavo informe del señor Alain Pellet, relator especial sobre las reservas a los tratados, 27 de mayo y 10 de julio de 2003, Nueva York, Naciones Unidas, 2003, p. 47 (A/CN.4/535 y Add.1).

30 Cameron, Iain, op. cit., para. 4.

31 Ibidem, paras. 7 y 8.

32 Ibidem, para. 8 . 
Esta revista forma parte del acervo de la Biblioteca Jurídica Virtual del Instituto de Investigaciones Jurídicas de la UNAM

Sin embargo, la práctica estatal es incoherente en la materia. ${ }^{33} \mathrm{Al}$ respecto, las características de la interpretación de los tratados y sus disposiciones han sido analizadas por Fernández de Casadevante Romani, quien destaca que se trata de una operación compleja que indica lo que es y no lo que debe ser la norma, aclarando que no consiste en una revisión de ésta. ${ }^{34}$ En efecto, el autor subraya que ésta es la finalidad del artículo 31 de la Convención de Viena sobre el Derecho de los Tratados de 1969, al conferirle una "naturaleza única" de interpretación y reconociendo la buena fe a partir del principio pacta sunt servanda, a la luz del significado que emerge del contexto del tratado, sus objetivos y sus fines vigentes al momento de su celebración. ${ }^{35}$

Finalmente, este jurista sostiene que, de conformidad con el párrafo 1 del artículo señalado, la tarea de interpretación presume una manifestación auténtica, al punto de no requerirse, ab initio, el análisis de la intención del celebrante. No obstante, la norma admite la consideración de una hipótesis de significado especial a aplicarse por el intérprete, con el objeto de salvaguardar los diferentes significados que podrían presentarse y evitar errores. En otras palabras, se trata de una disposición que apunta obtener una auténtica expresión de la voluntad para una de las partes, que no necesariamente puede ser la voluntad común, ${ }^{36}$ con la finalidad de impedir cualquier controversia sobre la intención del Estado parte y su entendimiento. ${ }^{37}$

33 Ibidem, para. 10.

34 Fernández de Casadevante Romani, Carlos, Sovereignty and Interpretation of International Norms, Berlín-Heidelberg-Nueva York, Springer, 2007, p. 45.

$35 \mathrm{Ibidem}, \mathrm{pp} .46$ y 47. El último criterio que hemos referido fue aplicado por la CIJ en distintos asuntos, como el caso sobre la Plataforma Continental del Mar Egeo, entre Grecia y Turquía. Cfr. Aegean Sea Continental Shelf, Judgment, ICJ Reports 1978, p. 3.

36 La importancia de la "voluntad común" en materia de interpretación de tratados fue reconocida por la CPIJ en los asuntos Nationality Decrees in Tunis and Morocco, P.CIJ, Advisory Opinion of 7 February 1923 (Serie B, núm. 4), y Access to, or anchorage in, the Port of Danzig, of Polish war vessels, P.CIJ, Advisory Opinion of 11 December 1931 (Serie A/B, núm. 43).

37 Fernández de Casadevante Romani, Carlos, op. cit., pp. 46-47. Con relación a las interpretaciones auténticas, Casado Raigón sostiene que aquélla es realizada por las propias partes en el tratado y es consecuencia de un acuerdo expreso o una práctica al respecto. C $f$ r. Casado Raigón, Rafael, Derecho internacional, 2a. ed., Madrid, Tecnos, 2015, p. 194. 
Esta revista forma parte del acervo de la Biblioteca Jurídica Virtual del Instituto de Investigaciones Jurídicas de la UNAM

\section{LA CONTRIBUCIÓN DE LA COMISIÓN DE DERECHO INTERNACIONAL Y LA GUIÍA DE LA PRÁCTICA SOBRE LAS RESERVAS A LOS TRATADOS}

El trabajo de la CDI comenzó en 1993 bajo la dirección del relator especial Alain Pellet, quien presentó su Primer Informe en 1995 destinado a identificar los problemas no resueltos en las convenciones de Viena de 1969, 1978 y 1986, que contienen normas inconclusas u oscuras, y, a la vez, en menor medida trata el tema de las declaraciones interpretativas, a las que no se hace referencia en absoluto en esas convenciones.

Sin embargo, Pellet dedica especial atención a las "reservas" y el resultado de la controversia entre los partidarios de la universalidad, que consideraban a una reserva contraria al "objeto y fin del tratado" como nula en sí misma, independientemente de las reacciones de las demás partes, y los adeptos de la integridad, que sostenían, como criterio de validez, que debían considerarse las objeciones que formulen los demás Estados, siendo este último aspecto vinculado especialmente con las "declaraciones interpretativas”, a las que había que adicionar la escasa información sobre la práctica en la materia y que el relator especial solucionó mediante la confección de cuestionarios dirigidos a los gobiernos. ${ }^{38}$

Pellet, quien finalizó su labor en 2011, no se orientó a la redacción de un texto de espíritu convencional ni a convocar a una conferencia multilateral, sino a establecer un conjunto de directrices a través de una "guía" que oriente la práctica de los Estados y los organismos internacionales.

En materia de declaraciones interpretativas, la Comisión procuró lograr una definición y brindar las herramientas para la distinción entre las reservas, las declaraciones interpretativas y aquéllas caracterizadas como "condicionales", incluyendo el régimen jurídico aplicable a éstas. ${ }^{39} \mathrm{Al}$ respecto, cabe señalar que varias delegaciones se mostraron partidarias de equipararlas a las reservas y renunciar a los proyectos de directrices que se refieran a ellas y, en particular, a las denominadas "declaraciones interpretativas condicionales". ${ }^{40}$

38 Resolución AG 50/45.

39 Pellet, Alain, "The ILC Guide to Practice on Reservations to Treaties: A General Presentation by the Special Rapporteur”, The European Journal of International Law, vol. 24, núm. 4, 2013, p. 1082.

40 CDI, Informe de la Comisión de Derecho Internacional, 55o. periodo de sesiones, cit., p. 40. 
Esta revista forma parte del acervo de la Biblioteca Jurídica Virtual del Instituto de Investigaciones Jurídicas de la UNAM

En concreto, el texto final de la Guía de la Práctica sobre las Reservas a los Tratados, aprobado por la CDI en su 63o. periodo de sesiones, contiene disposiciones que contribuyen a un mejor entendimiento de las declaraciones interpretativas. Por otro lado, los puntos 1.1.1-1.1.4 consideran como "reserva" a las declaraciones que tienen por objeto limitar las obligaciones de su autor. ${ }^{41}$

Por otra parte, el punto 1.2 define a las declaraciones interpretativas como “... una declaración unilateral, cualquiera que sea su enunciado o denominación, hecha por un Estado o por una organización internacional con objeto de precisar o aclarar el sentido o el alcance de un tratado o de algunas de sus disposiciones", y aclara, en el punto 1.2.1, que la formulación conjunta de estas declaraciones no altera su naturaleza unilateral..$^{42}$ En adición, el punto 4.7.1 señala los efectos de las declaraciones interpretativas, entendiendo que

1. Una declaración interpretativa no modifica las obligaciones resultantes del tratado. Sólo puede precisar o aclarar el sentido o el alcance que su autor atribuye a un tratado o a algunas de sus disposiciones y constituir, cuando proceda, un elemento que se ha de tener en cuenta en la interpretación del tratado de conformidad con la regla general de interpretación de los tratados.

2. En la interpretación del tratado también se tendrán en cuenta, cuando proceda, las reacciones de aprobación u oposición a la declaración interpretativa de otros Estados contratantes y organizaciones contratantes. ${ }^{43}$

De este modo, se hizo un intento de solución al distinguir entre las reservas y las declaraciones interpretativas, proponiendo su calificación como una u otra de acuerdo a los efectos jurídicos que el autor entendió como propios; para ello, se estableció un método en el punto 1.3.1, que propone, en esencia, una interpretación de la declaración de buena fe, conforme al sentido corriente que haya de atribuirse a sus términos, con miras a dilucidar la intención de su autor, a la luz del tratado a que se refiere. ${ }^{44}$

${ }^{41}$ CDI, Informe de la Comisión de Derecho Internacional, 63o. periodo de sesiones, cit., pp. 1 y 2 .

\footnotetext{
42 Ibidem, p. 2.

43 Ibidem, p. 25.

44 Ibidem, p. 2.
} 
Esta revista forma parte del acervo de la Biblioteca Jurídica Virtual del Instituto de Investigaciones Jurídicas de la UNAM

El punto 1.4 alude a las "declaraciones interpretativas condicionales", entendiéndolas como actos unilaterales formulados al firmar, ratificar, confirmar formalmente, aceptar o aprobar un tratado o al adherirse a él. Asimismo, el punto 1.4 contempla el supuesto de Estados que revisten carácter sucesor en un tratado que condiciona su consentimiento a una interpretación específica del acuerdo o de algunas de sus disposiciones. ${ }^{45}$

Sin embargo, en el punto 2.3.3, la Guía limita la posibilidad de excluir o modificar los efectos jurídicos de un tratado por medios distintos de las reservas, comprendiendo, en este supuesto, a las declaraciones unilaterales formuladas posteriormente y en virtud de una cláusula de opción. ${ }^{46}$

Los puntos 2.4 y 2.5 se refieren, respectivamente, al procedimiento relativo a las declaraciones interpretativas, su modificación y retiro. Su formulación debe ser realizada por escrito — preferiblemente - y por las autoridades que sean consideradas representantes del Estado o de la organización internacional para este fin, ${ }^{47}$ admitiendo su modificación ulterior, salvo que el tratado disponga otra cosa; ${ }^{48}$ por otro lado, su retiro puede llevarse a cabo en todo momento, siguiendo el mismo modo que su enunciación. ${ }^{49}$

Por otra parte, el punto 2.9 señala la inexistencia de presunciones, como regla, en materia de declaraciones interpretativas y las posibles reacciones a éstas: a) la aprobación o acuerdo con la interpretación del declarante; b) la oposición o desacuerdo a la formulación del declarante y formulando una declaración alternativa, y c) la recalificación, entendida como una reacción destinada a considerar a la declaración como una reserva. Las aprobaciones, las oposiciones y las recalificaciones pueden ser hechas en cualquier momento, preferiblemente por escrito y motivadas, de ser posible. ${ }^{50}$

En definitiva, la Guía constituye un documento útil para los profesionales del derecho internacional, con el objeto de orientar — sin sentido obligatorio - al lector en las imprecisiones que presenta el derecho de los

45 Ibidem, p. 3.

46 Ibidem, p. 7.

47 La Guía aclara que "El hecho de que una declaración interpretativa haya sido formulada en violación de una disposición del derecho interno de un Estado o de las reglas de una organización internacional concernientes a la competencia y el procedimiento para la formulación de declaraciones interpretativas no podrá ser alegado por ese Estado o esa organización como vicio de esa declaración”. Cfr. punto 2.4.3 (2). Ibidem, p. 8.

48 Idem.

49 Cfr. punto 2.5.12. Ibidem, p. 11

50 Ibidem, pp. 15 y 16. 
Esta revista forma parte del acervo de la Biblioteca Jurídica Virtual del Instituto de Investigaciones Jurídicas de la UNAM

tratados, como contribución al establecimiento de una certeza u oportunidad de solución, sin que afecte, de manera alguna, las disposiciones de las convenciones de Viena de 1969, 1978 y 1986.

\section{LA CONTRIBUCIÓN DE LOS TRIBUNALES INTERNACIONALES}

AL ESTUDIO DE LAS DECLARACIONES INTERPRETATIVAS EN GENERAL

A excepción de casos extraordinarios dentro de la generalidad, la labor de los tribunales internacionales no se dedica, especialmente, al estudio de las declaraciones interpretativas, y la mayoría de los Estados no parecen preocupados por éstas. Las razones, según Wood, se encuentran en la exigencia y demanda que genera en los ministerios de relaciones exteriores y sus equipos legales, a fin de afrontar una labor prolongada y difícil. ${ }^{51}$

El papel de la "interpretación”, entendida como indicación precisa del "sentido" y del "alcance" de un instrumento jurídicamente obligatorio, fue considerado por la Corte Permanente Internacional de Justicia, inicialmente, en el caso Jaworzina y, más tarde, en el caso de la Fábrica de Chorzów. ${ }^{52}$ Posteriormente, el tema fue objeto de estudio por la CIJ en la solicitud de interpretación del caso sobre Derecho de Asilo — al afirmar que la interpretación de los tratados tiene como objeto dilucidar el sentido y alcance de sus disposiciones -,${ }^{53}$ así como en la opinión consultiva en el asunto de la Interpretación de los Tratados de Paz, al dictaminar en este último que "interpretar" no significa "revisar" por cuanto

As the Court has declared in its Opinion of March 30th, 1950, the Governments of Bulgaria, Hungary and Romania are under an obligation to appoint their representatives to the Treaty Commissions, and it is clear that refusal to fulfil a treaty obligation involves international responsibility. Nevertheless, such a refusal cannot

51 Wood, Michael, "Institutional Aspects of the Guide to Practice on Reservations", The European Journal of International Law, vol. 24, núm. 4, 2013, p. 1099.

52 Question of Jaworzina (Polish-Czechoslovakian Frontier), P.CIJ, Judgment of December 6th, 1923 (Serie B, núm. 8), p. 37; Interpretation of Judgments Nos. 7 and 8 (Factory at Chorzów), P.CIJ, Judgment of December 16th, 1927 (Serie A, núm. 13), p. 10.

53 Request for interpretation of the Judgment of November 20th, 1950, in the asylum case, Judgment of November 27th, 1950, ICJ Reports 1950, p. 402. 
Esta revista forma parte del acervo de la Biblioteca Jurídica Virtual del Instituto de Investigaciones Jurídicas de la UNAM http://www.juridicas.unam.mx/ https://biblio.juridicas.unam.mx/bjv

https://revistas.juridicas.unam.mx/

DOI: http://dx.doi.org/10.22201/iij.24487872e.2018.18.12098

alter the conditions contemplated in the Treaties for the exercise by the SecretaryGeneral of is power of appointment. These conditions are not present in this case, and their absence is not made good by the fact that it is due to the breach of a treaty obligation. The failure of machinery for settling disputes by reason of the practical impossibility of creating the Commission provided for in the Treaties is one thing; international responsibility is another. The breach of a treaty obligation cannot be remedied by creating a Commission which is not the kind of Commission contemplated by the Treaties. It is the duty of the Court to interpret the Treaties, not to revise them. ${ }^{54}$

Sin embargo, en el desarrollo de su jurisprudencia más reciente, la Corte tuvo ocasión de referirse a las declaraciones interpretativas y su valor en el caso Delimitación marítima en el Mar Negro entre Rumania y Ucrania. ${ }^{55}$ En este asunto se planteó la validez de la declaración rumana a la Convención de las Naciones Unidas sobre el Derecho del Mar, con arreglo al artículo 309, formulada al momento de la firma y confirmada al hacerse la ratificación —el 17 de diciembre de 1996_- en los siguientes términos:

...3. Rumania declara que, con arreglo a las exigencias de equidad que resultan de los artículos 74 y 83 de la Convención sobre el Derecho del Mar, las islas deshabitadas y sin actividad económica propia no pueden afectar en modo alguno a la delimitación de los espacios marítimos pertenecientes a las costas principales de los Estados ribereños. ${ }^{56}$

En su sentencia del 3 de febrero de 2009, el Tribunal señaló que las declaraciones rumanas no podían tener por objeto excluir o modificar los efectos jurídicos de las disposiciones de la Convención, y que su aplicación debía

54 Interpretation of Peace Treaties (second phase), Advisory Opinion, ICJ Reports 1950, pp. 228 y 229.

55 Maritime Delimitation in the Black Sea (Romania v. Ukraine), Judgment, ICJ Reports 2009, p. 61.

56 La declaración textual en inglés expresa: “...3. Romania states that according to the requirements of equity —as it results from articles 74 and 83 of the Convention on the Law of the Sea - the uninhabited islands without economic life can in no way affect the delimitation of the maritime spaces belonging to the mainland coasts of the coastal States". Cfr. "Declaraciones y manifestaciones de los Estados parte de la Convención de las Naciones Unidas sobre el Derecho del Mar de 1982”, disponible en: http://www.un.org/Depts/los/convention_agree ments/convention_declarations.htm\#Argentina\%20Upon\%20signature (fecha de consulta: 24 de diciembre de 2016). La traducción es propia. 
Esta revista forma parte del acervo de la Biblioteca Jurídica Virtual del Instituto de Investigaciones Jurídicas de la UNAM

sujetarse al artículo 310 de la Convención, aunque aclaró que, en el caso analizado, las mismas no poseían incidencia alguna como tales:

...Finally, regarding Romania's declaration, quoted in paragraph 35 above, the Court observes that under Article 310 of UNCLOS, a State is not precluded from making declarations and statements when signing, ratifying or acceding to the Convention, provided these do not purport to exclude or modify the legal effect of the provisions of UNCLOS in their application to the State which has made a declaration or statement. The Court will therefore apply the relevant provisions of UNCLOS as interpreted in its jurisprudence, in accordance with Article 31 of the Vienna Convention on the Law of Treaties of 23 May 1969. Romania's declaration as such has no bearing on the Court's interpretation. ${ }^{57}$

Lo anterior resulta más evidente si se recuerda, además, que en lo concerniente a las actividades armadas en el territorio del Congo, la CIJ consideró la eventual pérdida de validez de una declaración unilateral que entra en colisión normativa con una disposición de ius cogens, al considerar que

In so far as the DRC contended further that Rwanda's reservation is in conflict with a peremptory norm of general international law, it suffices for the Court to note that no such norm presently exists requiring a State to consent to the jurisdiction of the Court in order to settle a dispute relating to the Genocide Convention. Rwanda's reservation cannot therefore, on such grounds, be regarded as lacking legal effect. ${ }^{58}$

Por otra parte, una contribución distinta es realizada por la Corte Interamericana de Derechos Humanos (CoIDH), que ha reflexionado sobre el objeto y fin de las declaraciones de los Estados en relación con el artículo 62 de la Convención Americana sobre Derechos Humanos (CADH), particularmente sus dos primeros incisos, en función de su jurisdicción. ${ }^{59}$ Por

57 Maritime Delimitation in the Black Sea (Romania v. Ukraine), Judgment, ICJ Reports 2009, p. 78 , para. 42 .

58 Armed Activities on the Territory of the Congo (New Application: 2002) (Democratic Republic of the Congo v. Rwanda), Jurisdiction and Admissibility, Judgment, ICJ Reports 2006, p. 33, para. 69.

59 En efecto, la norma de la Convención señalada (también conocida como Pacto de San José) dispone lo siguiente: "1. Todo Estado parte puede, en el momento del depósito de su instrumento de ratificación o adhesión de esta Convención, o en cualquier momento posterior, declarar que reconoce como obligatoria de pleno derecho y sin convención especial, 
Esta revista forma parte del acervo de la Biblioteca Jurídica Virtual del Instituto de Investigaciones Jurídicas de la UNAM http://www.juridicas.unam.mx/ https://biblio.juridicas.unam.mx/bjv https://revistas.juridicas.unam.mx/ DOI: http://dx.doi.org/10.22201/iij.24487872e.2018.18.12098

ejemplo, la CoIDH consideró la cuestión que nos interesa cuando analizó las objeciones preliminares de Trinidad y Tobago en el caso Hilaire y afirmó, en el voto razonado del juez Cançado Trindade, que

En la teoría y práctica del derecho internacional se ha buscado distinguir una "reserva" de una "declaración interpretativa”, de conformidad con los efectos jurídicos que se pretende atribuir a una u a otra: así, si se pretende aclarar el sentido o alcance de una determinada disposición convencional, trátase de una declaración interpretativa, mientras que si se pretende modificar una determinada disposición convencional o excluir su aplicación, trátase de una reserva. En la práctica, no siempre es fácil trazar la línea divisoria entre una y otra, como lo ilustra la controversia que ha circundado, en las últimas décadas, la cuestión de los efectos jurídicos de declaraciones insertadas en los instrumentos de aceptación de la cláusula facultativa de la jurisdicción obligatoria, dado el carácter sui generis de dicha cláusula... esto corresponde al "contexto", precisamente el segundo elemento integrante de la regla general de interpretación de los tratados consagrada en el artículo 31 de las dos Convenciones de Viena sobre Derecho de los Tratados. ${ }^{60}$

\section{En efecto, la CoIDH rechazó las declaraciones interpretativas del Estado demandado, al concluir que}

...el entendimiento avanzado en el cas d'espèce por el Estado demandado del alcance de su propia aceptación de la cláusula facultativa de la jurisdicción obligatoria de la Corte Interamericana, no resiste a la hermenéutica del artículo 62 de la Convención Americana, desarrollada a la luz de los cánones de interpretación del derecho de los tratados. ${ }^{61}$

En conclusión, consideramos que las declaraciones unilaterales formuladas por los Estados como “declaraciones interpretativas" pueden, en un argu-

la competencia de la Corte sobre todos los casos relativos a la interpretación o aplicación de esta Convención. 2. La declaración puede ser hecha incondicionalmente, o bajo condición de reciprocidad, por un plazo determinado o para casos específicos. Deberá ser presentada al Secretario General de la Organización, quien transmitirá copias de la misma a los otros Estados miembros de la Organización y al Secretario de la Corte”.

60 Corte IDH, Caso Hilaire vs. Trinidad y Tobago. Excepciones preliminares. Sentencia del 10. de septiembre de 2001 (Serie C, núm. 80), p. 11, para. 30, disponible en: http: / www.corteidh. or.cr/docs/casos/articulos/Seriec_80_esp.pdf (fecha de consulta: 1o. de noviembre de 2016).

61 Ibidem, pp. 11 y 12 , paras. 31 y 32. 
Esta revista forma parte del acervo de la Biblioteca Jurídica Virtual del Instituto de Investigaciones Jurídicas de la UNAM

mento similar al establecido por la CIJ en el caso Delimitación marítima en el Mar Negro, no tener incidencia alguna en un caso puntual, aunque ello no impide que aquéllas carezcan de valor como medio de prueba o interpretación, de conformidad con el artículo 31 de las convenciones de Viena sobre el Derecho de los Tratados de 1969, 1978 y 1986.

\section{Tipos DE DECLARACIONES AUTORIZADAS EN LA CONVENCIÓN de las NaCiones Unidas Sobre El Derecho del Mar. Examen DE LOS ARTÍ́CULOS 287, 298 Y 310}

\section{Las declaraciones autorizadas. Características, límites y excepciones}

A pesar de la prohibición general de reservas y excepciones dispuesta en la propia Convención de 1982, el artículo 310 se refiere a las declaraciones y manifestaciones autorizadas. Esta norma permite a los Estados y entidades la formulación de afirmaciones o declaraciones sobre su aplicación, que pueden realizarse al momento de firmar, ratificar o adherirse a la misma, siempre que no tengan como objeto excluir o modificar el efecto jurídico de sus disposiciones. En efecto, el artículo 310 establece que

El artículo 309 no impedirá que un Estado, al firmar o ratificar esta Convención o adherirse a ella, haga declaraciones o manifestaciones, cualquiera que sea su enunciado o denominación, a fin de, entre otras cosas, armonizar su derecho interno con las disposiciones de la Convención, siempre que tales declaraciones o manifestaciones no tengan por objeto excluir o modificar los efectos jurídicos de las disposiciones de la Convención en su aplicación a ese Estado.

La norma posee una particular naturaleza advertida por Oxman, quien señala que los Estados negociadores fueron conscientes de la relación entre las excepciones al sistema de solución de controversias tendientes a decisiones obligatorias y los riesgos que representaba la posible utilización de las reservas, explicando la relación entre los artículos 309 y 310 de la Convención. ${ }^{62}$

62 Oxman, Bernard H., "The Third United Nations Conference on the Law of the Sea:The Ninth Session (1980)”, American Journal of International Law, vol. 75, núm. 2, 1981, p. 232. Al 
Esta revista forma parte del acervo de la Biblioteca Jurídica Virtual del Instituto de Investigaciones Jurídicas de la UNAM http://www.juridicas.unam.mx/ https://biblio.juridicas.unam.mx/bjv

https://revistas.juridicas.unam.mx/

DOI: http://dx.doi.org/10.22201/iij.24487872e.2018.18.12098

De este modo, una interpretación armónica de ambas normas remite a dos supuestos de habilitación de declaraciones del tipo "electivo": a) la dispuesta en el artículo 287, que señala un régimen de libre elección conocido como "fórmula Montreux", que enumera cuatro medios a disposición de las partes y respecto del cual pueden optar al firmar o ratificar la Convención o adherirse a ella — el Tribunal Internacional del Derecho del Mar, la CIJ, el arbitraje y el arbitraje especial— ${ }^{63}$ y de presentarse una disputa y no coincidir las partes en la elección, se reconoce en forma residual la opción arbitral prevista en el Anexo VII de la Convención, ${ }^{64}$ y b) las declaraciones

respecto, H. Gary Knight ya había identificado que el sistema de solución de controversias era uno de los puntos más complejos de la III Conferencia en relación con el uso de las reservas y su importante rol respecto de la política oceánica de los Estados Unidos. En cuanto a la falta de acuerdo, este autor afirmó que una minoría insatisfecha con el texto final podría presentar reservas a fin de eximirse del procedimiento de solución de controversias, con las posteriores objeciones de los demás Estados a éstas, estableciendo un contratiempo evidente: la ausencia de comprensión disponible para resolver las disputas. En consecuencia, Knight sugirió prohibir toda reserva en la futura convención, aunque identificó dos riesgos adicionales: “(1) as noted above, it could have the effect of reducing the number of adherents to the treaty, forcing some nations which would otherwise ratify to abstain from doing so in order to avoid being bound by a compulsory dispute settlement provision; and (2) it would present an obstacle to nations who wish compulsory dispute settlement but which might object to another treaty provision in such degree as to wish the right to attach a reservation to its ratification. Obviously, the prohibition of reservations is a two-edged sword". Cfr. Knight, H. Gary, "The Potential Use of Reservations to International Agreements Produced by the Third United Nations Conference on the Law of the Sea”, Policy Issues in Ocean Law, Studies in Transnational Legal Policy, American Society of International Law, 1975, núm. 8, pp. 18 y 19.

63 Aspecto detallado en el Anexo VIII de la Convención, aplicable a las controversias de pesquerías, protección y preservación del medio marino, investigación científica marina y navegación.

64 Argentina, al ratificar la Convención, optó, en primer término, por la jurisdicción del Tribunal Internacional del Derecho del Mar y, en segunda opción, por un tribunal arbitral constituido de conformidad con el Anexo VIII para cuestiones relativas a pesquerías, protección y preservación del medio marino, investigación científica marina y navegación (disponible en: http: / / www.itlos.org/fileadmin/itlos/documents / basic_texts/287_declarations_041111_english.pdf [fecha de consulta: 30 de diciembre de 2016]). Asimismo, Argentina excluyó, de conformidad con las excepciones facultativas a la aplicabilidad de la sección 2, las clases de controversias indicadas en el artículo 298, párrafo 1, incisos $a, b$ y c (disponible en: http://www.itlos.org/fi leadmin/itlos/documents/basic_texts/298_declarations_June_2011_english.pdf [fecha de consulta: 23 de diciembre de 2016]). En relación con las declaraciones de jurisdicción obligatoria, Guerrero Peniche y Rodríguez Cedeño afirman que éstas constituyen, formalmente, declaraciones unilaterales sui generis. En este sentido, véase Guerrero Peniche, Nicolás y Rodríguez Cedeño, Víctor, "Los actos unilaterales de los Estados en derecho internacional: los trabajos de codifica- 
Esta revista forma parte del acervo de la Biblioteca Jurídica Virtual del Instituto de Investigaciones Jurídicas de la UNAM

tendientes al establecimiento de límites y excepciones a los denominados "procedimientos obligatorios conducentes a decisiones obligatorias", dispuestos en la sección 2 de la parte XV de la Convención, estableciendo así una evasión al problema de las reservas, al habilitar la sección 3, titulada "Limitaciones y excepciones a la aplicabilidad de la sección 2", que identifica las controversias que merecen excluirse con una mera declaración del Estado o entidad interesada.

Principalmente, las excepciones y los límites surgen de una lectura armónica de los artículos 297 y 298 de la Convención respecto de una o varias de las siguientes categorías de controversias, referidas a: 1) la interpretación o la aplicación de los artículos 15, 74 y 83, concernientes a la delimitación de las zonas marítimas, o las relativas a bahías o títulos históricos; ${ }^{65}$ 2) actividades militares, ${ }^{66}$ y 3) las controversias respecto de las cuales el Consejo de Seguridad de las Naciones Unidas ejerza las funciones que le confiere la Carta ${ }^{67}$ En otras palabras, se tratan de disputas referidas al ejercicio de las libertades tradicionales en la alta mar, la zona económica exclusiva o las controversias de soberanía asociadas a intereses nacionales vitales que los Estados no desean someter.

Al respecto, Klein sostiene que estas excepciones carecen de autosuficiencia, toda vez que

These exceptions are not self-judging and cannot serve as a simple bar to proceedings under Section 2. It is for the court or tribunal to determine whether it has jurisdiction to decide a particular matter. Even if a State has opted to exclu-

ción en la Comisión de Derecho Internacional”, Anuario Mexicano de Derecho Internacional, vol. III, 2003, p. 217.

65 A condición de que el Estado que haya hecho una declaración de esa índole, cuando una controversia de ese tipo surja después de la entrada en vigor de esta Convención y no se llegue a un acuerdo dentro de un periodo razonable en negociaciones entre las partes, acepte, a petición de cualquier parte en la controversia, que la cuestión sea sometida al procedimiento de conciliación previsto en la sección 2 del Anexo V; además, quedará excluida de tal sumisión toda controversia que entrañe necesariamente el examen concurrente de una controversia no resuelta respecto de la soberanía u otros derechos sobre un territorio continental o insular.

66 Para un análisis del concepto de las actividades militares y el derecho del mar, véase Godio, Leopoldo M. A., "La Convención de las Naciones Unidas sobre el Derecho del Mar de 1982 y las actividades militares”, Revista de la Facultad de Derecho, Universidad de la República, núm. 39, julio-diciembre de 2015, pp. 97-118.

67 Con la excepción de que el asunto sea retirado de su orden del día o solicite a las partes que lo solucionen por los medios previstos en esta Convención. 
Esta revista forma parte del acervo de la Biblioteca Jurídica Virtual del Instituto de Investigaciones Jurídicas de la UNAM

de a certain category of dispute, the disputant parties may still agree to use the Convention's procedures. ${ }^{68}$

En definitiva, las controversias referidas a la interpretación y aplicación de la Convención de 1982 sólo pueden ser resueltas mediante las opciones allí previstas y siempre que no se encuentren excluidas a través de declaraciones previstas en el artículo 298 y de conformidad con los límites establecidos en el artículo 309. No obstante, lo anterior no excluye que las partes, para intentar solucionar su diferendo, acuerden otros medios jurisdiccionales para su resolución, con fundamento en una cláusula de habilitación dispuesta en un convenio especial, tal y como ocurrió en el caso del Atún de Aleta Azul. ${ }^{69}$

Planteado en distintos términos, la consecuencia a nivel de compromisos asumidos e inspirada en la solución pacífica de controversias puede parecer carente de herramientas, pero no debe olvidarse la existencia del principio establecido en el artículo 2.3 de la Carta de las Naciones Unidas y las disposiciones de su capítulo VI, al cual se adiciona la opinión de la comunidad internacional y las eventuales negociaciones diplomáticas para influir en el comportamiento de los Estados parte, con el fin de encontrar una solución que satisfaga sus expectativas para esta particular clase de asuntos que, sin duda, aparecen como políticamente más críticos que otros. ${ }^{70}$

\section{Las declaraciones realizadas por los Estados con arreglo al artículo 298} de la Convención y las actividades militares

La expresión "actividades militares" sólo aparece expresamente una vez en el texto de la Convención y sus anexos: en el artículo 298, párrafo 1, inciso

68 Klein, Natalie, Dispute Settlement in the UN Convention on the Law of the Sea, Cambridge, Cambridge University Press, 2004, p. 123.

69 Para un análisis detallado de la controversia, véase Romano, Cesare, "The Southern Bluefin Tuna Dispute: Hints of a World to Come... Like It or Not”, Ocean Development \& International Law, núm. 32, 2001, pp. 313-348.

70 En efecto, Natalie Klein afirma que "While mandatory jurisdiction is either not necessary in some cases, or not politically viable in others, it is notable that a small proportion of States parties has as yet availed themselves of these exceptions. 4 Such reticence, while a surprising deviation, may increase the likelihood of States using adjudication or arbitration for the future resolution of disputes on these issues, rather than just relying on consent-based modes of dispute settlement”. Cfr. Klein, Natalie, op. cit., pp. 227 y 228. 
Esta revista forma parte del acervo de la Biblioteca Jurídica Virtual del Instituto de Investigaciones Jurídicas de la UNAM

$b$. Allí se enumera a estas actividades como una de las excepciones facultativas a los procedimientos obligatorios, conducentes a decisiones obligatorias, previstos en la parte XV de la Convención, al señalar la posible exclusión de las "...controversias relativas a actividades militares, incluidas las actividades militares de buques y aeronaves de Estado dedicados a servicios no comerciales...". ${ }^{71}$

Uno de los posibles fundamentos para su inclusión de este modo en el texto de la Convención se encuentra en la consideración del poder naval ${ }^{72} \mathrm{como}$ pilar histórico de las políticas militares de los Estados que eran potencia en la materia. ${ }^{73} \mathrm{Al}$ respecto, Klein confirma este criterio de promoción de intereses nacionales fundados en las clásicas libertades del mar y afirma que estos principios se proyectaron a distintas actividades, como ejercicios navales, pruebas de armas, misiones de presencia naval, instalación de estructuras y dispositivos militares o declaraciones de zonas de seguridad, entre otras. ${ }^{74}$

La misma jurista sostiene que la Convención proporciona poca información respecto de los modos y las conductas militares permitidas en los diferentes espacios marítimos, y que ello se justifica en el deseo de excluir esta actividad de su ámbito de competencia y examen. En efecto, se señala la regulación de actividades de los buques de guerra y aeronaves y aeronaves no comerciales, aspecto reconocido en el derecho de paso inocente por el mar territorial, dispuesto en el artículo 29, sección 3, subsección “C”, parte II, de la Convención. ${ }^{75}$

71 Convención de las Naciones Unidas sobre el Derecho del Mar, adoptada el 30 de abril de 1982, United Nations Treaty Series, vol. 1833, artículo 298, párrafo 1, inciso b. Para un mayor análisis, véase Janis, Mark W., "Dispute Settlement in the Law of the Sea Convention: The Military Activities Exception”, Ocean Development \&International Law, vol. 4, núm. 1, 1977, pp. 51-65.

72 Hedley Bull explicó la idea del "poder naval” y sus características, de modo que una fuerza naval puede ser guiada y utilizada con el objeto de transmitir amenazas, proporcionar tranquilidad u obtener prestigio de una manera "omnipresente" que las fuerzas armadas o aéreas no les es permitido. Cfr. Bull, Hedley, "Sea Power and Political Influence”, Power at Sea I:The New Environment-Adelphi Paper 16, núm. 122, 1976, p. 6.

73 Autores como Keohane y Nye sostienen que el régimen de la libertad de los mares, imperante hasta el siglo XX, fue estrechamente asociado a los intereses y al poderío del principal país naval —el Reino Unido- al permitírsele dominar las periferias del mundo con el fin de garantizar, mediante la fuerza militar, la libertad del comercio y de los océanos, dando lugar a la denominada Pax Britannica, entre 1815 y 1914. Cfr. Keohane, Robert y Nye, Joseph, Poder e interdependencia. La política mundial en transición, Buenos Aires, GEL, 1988, p. 89.

74 Klein, Natalie, op. cit., pp. 279 y 280.

75 Ibidem, p. 280. 
Esta revista forma parte del acervo de la Biblioteca Jurídica Virtual del Instituto de Investigaciones Jurídicas de la UNAM http://www.juridicas.unam.mx/ https://biblio.juridicas.unam.mx/bjv https://revistas.juridicas.unam.mx/ DOI: http://dx.doi.org/10.22201/iij.24487872e.2018.18.12098

En relación con el artículo 298, se afirma que los límites de las exclusiones no resultan evidentes y se presenta una amplia gama de controversias que pueden ser potencialmente objeto de exención, considerando además que

...the variety of disputes that are excepted from mandatory jurisdiction at the option of States under Article 298 (1) (b) and (c), and considers what the absence of compulsory dispute settlement may mean for the international rules governing these activities... the possible application of UNCLOS during times of armed conflict as well as military activities that do not amount to armed conflict. Both the military activities and the Security Council exceptions may be relevant here in addition to certain questions of admissibility... various rights of passage accorded to military and government vessels in areas subject to coastal State sovereignty and the role of dispute settlement for these legal regimes... the question of law enforcement and addresses the particular law enforcement disputes specifically envisaged under Article 298 as well as other law enforcement activities under the Convention. With respect to the latter, difficulties may arise in determining where a line should be drawn between what constitutes law enforcement that is subject to mandatory jurisdiction and what constitutes military activities for the purposes of the optional exceptions. ${ }^{76}$

En su estudio, Klein concluye que las actividades militares, el uso de la fuerza en el mar y la aplicación de sus normas en estos escenarios presentan un desarrollo normativo mínimo en la Convención, caracterizado por una vaguedad deliberada que permite a los Estados excluir las controversias sobre éstas, incluso cuando amenazan a la paz y la seguridad internacionales, beneficiando así a las grandes potencias navales y su capacidad política ante acciones de operación naval en el mar territorial o la zona económica exclusiva de terceros Estados. ${ }^{77}$

Lo anterior pone de manifiesto la importancia que tienen las declaraciones de los Estados parte de la Convención de las Naciones Unidas sobre el

76 Ibidem, p. 281.

77 La autora afirma, textualmente, que "The implication from this procedural device is that international legal processes are not necessarily required as the means to resolve disputes relating to armed conflict and naval activities in maritime areas where the freedoms of the high seas are exercised. The military activities exception and the Security Council exception can work to the advantage of States with greater naval power if they wish to resolve these disputes through political avenues”. Ibidem, p. 313. 
Esta revista forma parte del acervo de la Biblioteca Jurídica Virtual del Instituto de Investigaciones Jurídicas de la UNAM

Derecho del Mar de 1982 y su incidencia directa en el sistema de solución obligatorio de controversias y su rol fundamental, no sólo respecto de la exclusión — O no - de las actividades militares, sino también con relación a las declaraciones interpretativas que se realizan respecto de ellas, a fin de garantizar el equilibrio de la Convención, siguiendo el espíritu del consenso que signó su negociación.

Advertida, entonces, la importancia de las declaraciones de los Estados en relación con el artículo 298 de la Convención, un relevamiento de éstas demuestra que aquéllos no se limitaron — simplemente a su mera mención - a formular las exclusiones de su elección, sino que, en más de un caso, realizaron aclaraciones que podrían contemplarse como declaraciones o manifestaciones autorizadas por el artículo 310, en tanto intentan armonizar su derecho interno con las disposiciones de la Convención y formulan contribuciones para un mejor entendimiento de ella.

No obstante, un grupo menor de Estados se valió de la norma para manifestar cuestionables declaraciones que, bajo una apariencia de declaración interpretativa, intentan ampliar o modificar los supuestos y efectos previstos en los artículos 298 y 297, párrafos 2 y 3, con un objeto inmediato evidente: evitar ser potencialmente demandados.

Entre ellos se destaca la declaración de la Federación de Rusia, que fue objeto de análisis por parte del Tribunal Internacional de las Naciones Unidas para el Derecho del Mar en el caso del Arctic Sunrise, en 2013. ${ }^{78}$ La declaración rusa afirma que este Estado

...no acepta los procedimientos previstos en la Sección 2 de la Parte XV de la Convención que entrañen decisiones de carácter vinculante relacionadas con con-

78 The Arctic Sunrise Case (Kingdom of the Netherlands v. Russian Federation), ITLOS, Provisional Measures, Order of 22 November 2013. Para una descripción del procedimiento en el Tribunal de Hamburgo, véase Godio, Leopoldo M. A., "El asunto del Arctic Sunrise y el sistema de solución de controversias de la Convención de Naciones Unidas sobre el Derecho del Mar", elDial.com, Buenos Aires, 12 de diciembre de 2013. Se trata de un asunto "hermanado" con el ARA Libertad Case entre Argentina y Ghana, respecto del cual nos referiremos más adelante, si se considera que el Estado del pabellón del buque obtuvo la liberación de un buque mediante una solicitud de medidas provisionales. Para un estudio sobre el tema, véanse Godio, Leopoldo M. A. y Rosenthal, Julián M., "The Prompt Release of Vessels in Provisional Measures Procedures. New Trends and Challenges?”, Revista Tribuna Internacional, vol. 4, núm. 7, 2015 , pp. 43-67; Guilfoyle, Douglas y Miles, Cameron A., "Provisional Measures and the MV Arctic Sunrise”, American Journal of International Law, vol. 108, núm. 2, 2014, pp. 271-287. 
troversias sobre la interpretación o la aplicación de los artículos 15, 74 y 83 de la Convención, la delimitación del mar territorial o relativas a bahías o derechos históricos; controversias sobre actividades militares, incluidas las actividades militares que lleven a cabo buques y aeronaves de Estado, controversias sobre actividades de mantenimiento del orden relacionadas con el ejercicio de derechos de soberanía o de jurisdicción; ni con controversias a cuyo respecto el Consejo de Seguridad de las Naciones Unidas este cumpliendo las funciones que le corresponden con arreglo a la Carta de las Naciones Unidas. La Federación de Rusia, teniendo presentes los artículos 309 y 310 de la Convención, declara que rechaza cualesquiera declaraciones o afirmaciones que se hayan formulado en el pasado o se formulen en el futuro con ocasión de la firma o ratificación de la Convención o la adhesión a ella, o que realicen por cualquier otra razón en relación con la Convención, que sean incompatibles con las disposiciones del artículo 310 de la Convención. A juicio de la Federación, cualquiera que sea su denominación o la forma en que estén redactadas, estas declaraciones o afirmaciones no podrán menoscabar ni modificar los efectos jurídicos de las disposiciones de la Convención por lo que respecta a su aplicación a la parte en la Convención que haya formulado esas declaraciones o afirmaciones, por lo cual la Federación de Rusia no las tendrá en cuenta en sus relaciones con esa parte en la Convención. ${ }^{79}$

79 Al momento de la firma, Rusia había declarado oportunamente lo siguiente: "1. La Unión de Repúblicas Socialistas Soviéticas declara que, en virtud del artículo 287 de la Convención de las Naciones Unidas sobre el Derecho del Mar, elige un tribunal arbitral constituido de conformidad con el Anexo VII como procedimiento básico para la solución de controversias respecto de la interpretación o aplicación de la Convención. Opta por un tribunal arbitral especial constituido de conformidad con el Anexo VIII para el examen de las cuestiones relativas a las pesquerías, la protección y preservación del medio marino, la investigación científica marina y la navegación, incluida la contaminación causada por buques o por vertimiento. Reconoce la competencia del Tribunal Internacional del Derecho del Mar, en la forma estipulada en el artículo 292, en cuestiones relativas a la pronta liberación de buques retenidos y de sus tripulantes; 2. De conformidad con lo dispuesto en el artículo 298 de la Convención, la Unión de Repúblicas Socialistas Soviéticas declara que no acepta los procedimientos obligatorios conducentes a decisiones obligatorias para el examen de las controversias relativas a la delimitación del mar territorial, las controversias relativas a actividades militares y las controversias respecto de las cuales el Consejo de Seguridad de las Naciones Unidas ejerza las funciones que se le asignan en la Carta de las Naciones Unidas". Cfr. "Declaraciones y manifestaciones de los Estados parte de la Convención de las Naciones Unidas sobre el Derecho del Mar de 1982", disponible en: http://www.un.org/Depts/los/con vention_agreements/convention_declarations.htm\#Argentina\%20Upon\%20signature (fecha de consulta: 24 de diciembre de 2016). 
Esta revista forma parte del acervo de la Biblioteca Jurídica Virtual del Instituto de Investigaciones Jurídicas de la UNAM

Respecto de esta declaración, a la luz del caso del Arctic Sunrise, la conducta de la Federación de Rusia fue negarse a participar en el proceso, al interpretar que el tribunal arbitral a constituirse de conformidad con el Anexo VII de la Convención y el Tribunal de Hamburgo, respecto del procedimiento de medidas provisionales, carecían ambos de competencia y jurisdicción en el asunto, en razón de las manifestaciones rusas formuladas con arreglo al artículo 298 de la Convención ya referido.

El Tribunal de Hamburgo, en virtud de las conductas asumidas por las partes y luego de verificar la existencia de una controversia, la urgencia de la medida solicitada y la jurisdicción prima facie del tribunal a conformarse de acuerdo con el Anexo VII de la Convención, emitió su Orden de medidas provisionales el 22 de noviembre de 2013, decretando la liberación del buque mediante el depósito de una fianza de 3.6 millones de euros. ${ }^{80}$

Distinto es el caso de Ucrania, que presenta un supuesto de interés al declarar no aceptar los procedimientos obligatorios conducentes a decisiones obligatorias para el examen de las controversias relativas a la delimitación de las zonas marítimas o relativas a bahías o títulos históricos, así como respecto de actividades militares, a menos que exista para estas últimas un tratado internacional entre Ucrania y los Estados que prevea lo contrario. ${ }^{81}$

Entre las declaraciones de interés que amplían, directa o indirectamente, los preceptos dispuestos en la norma analizada, la República Democrática Alemana manifestó que, según la Convención, “...el Estado ribereño no disfruta de derechos residuales en la zona económica exclusiva. En particular, los derechos y la jurisdicción del Estado ribereño en esa zona no incluyen los derechos a obtener una notificación de los ejercicios o maniobras militares o a autorizarlos...”; por su parte, el gobierno de la República Popular de Bangladesh declaró que “...entiende que las disposiciones de la Convención no autorizan a otros Estados a llevar a cabo en la zona econó-

80 The Arctic Sunrise Case (Kingdom of the Netherlands v. Russian Federation), ITLOS, Provisional Measures, Order of 22 November 2013. El fondo del asunto, actualmente en trámite, fue aceptado por el tribunal arbitral en 2014. Cfr. The Arctic Sunrise Arbitration (Netherlands v. Russia), Award on Jurisdiction dated 26 November 2014, disponible en: http: / /www.pcacases.com / web/view/21 (fecha de consulta: 2 de diciembre de 2016).

81 "Declaraciones y manifestaciones de los Estados parte de la Convención de las Naciones Unidas sobre el Derecho del Mar de 1982", disponible en: http://www.un.org/Depts/los/con vention_agreements/convention_declarations.htm\#Argentina\%20Upon\%20signature (fecha de consulta: 24 de diciembre de 2016). 
Esta revista forma parte del acervo de la Biblioteca Jurídica Virtual del Instituto de Investigaciones Jurídicas de la UNAM http://www.juridicas.unam.mx/ https://biblio.juridicas.unam.mx/bjv https://revistas.juridicas.unam.mx/ DOI: http://dx.doi.org/10.22201/iij.24487872e.2018.18.12098

mica exclusiva y sobre la plataforma continental actividades o maniobras militares, en particular las que entrañen el uso de armas o explosivos, sin el consentimiento del Estado ribereño...”. En idéntico criterio, la República Federativa de Brasil expresó que “... las disposiciones de la Convención no autorizan a otros Estados a realizar ejercicios o maniobras militares, en especial los que involucren el uso de armas o materiales explosivos, en la zona económica exclusiva sin el consentimiento del Estado ribereño". ${ }^{82}$

Similar razonamiento adoptó la República de la India, al entender que “... las disposiciones de la Convención no autorizan a otros Estados a llevar a cabo en la zona económica exclusiva y sobre la plataforma continental actividades o maniobras militares, en particular las que entrañen el uso de armas o explosivos, sin el consentimiento del Estado ribereño". Con un criterio semejante, Malasia declaró que “... las disposiciones de la Convención no autorizan a otros Estados a realizar ejercicios o maniobras militares, en especial los que involucren el uso de armas o materiales explosivos, en la zona económica exclusiva sin el consentimiento del Estado ribereño...”. Análoga declaración formuló la República Islámica de Pakistán, al manifestar que las disposiciones de la Convención no autorizan, en modo alguno, la realización de ejercicios o maniobras militares en la zona económica exclusiva o la plataforma continental de los Estados ribereños, primordialmente cuando entrañen el uso de armas o explosivos, excepto que cuenten con el respectivo consentimiento previo. También resulta ilustrativa la declaración del Reino de Tailandia, por cuanto

...entiende que, en la zona económica exclusiva, el goce de la libertad de comunicación internacional, de conformidad con su definición y con otras disposiciones pertinentes de la Convención, excluye cualquier uso no pacífico sin el consentimiento del Estado ribereño correspondiente, tales como ejercicios militares u otras actividades que pueden afectar a los derechos o intereses de dicho Estado; excluye también la amenaza o el uso de la fuerza contra la integridad territorial, la independencia política, la paz o la seguridad del Estado ribereño. ${ }^{83}$

Sin embargo, una de las declaraciones más interesantes es la formulada por la República del Uruguay, posiblemente inspirada en el caso de las Actividades

82 Idem.

83 Idem. 
Esta revista forma parte del acervo de la Biblioteca Jurídica Virtual del Instituto de Investigaciones Jurídicas de la UNAM

Militares en y contra Nicaragua, decidido por la CIJ, en $1986,{ }^{84}$ posterior a la realización de la III Conferencia de las Naciones Unidas sobre el Derecho del Mar. En efecto, Uruguay interpreta que

En la zona económica exclusiva, el disfrute de las libertades de comunicación internacional, de conformidad con su definición y con otras disposiciones pertinentes de la Convención, excluye cualesquiera usos no pacíficos sin el consentimiento del Estado ribereño, tales como ejercicios militares u otras actividades que puedan afectar los derechos o intereses de dicho Estado, y también excluye la amenaza o el uso de la fuerza contra la integridad territorial, la independencia política, la paz o la seguridad del Estado ribereño... Esta Convención no faculta a ningún Estado para construir, operar o utilizar instalaciones o estructuras en la zona económica exclusiva de otro Estado, tanto las previstas en la Convención como las de cualquier otra naturaleza, sin el consentimiento del Estado ribereño. ${ }^{85}$

Por otra parte, entre el grupo de Estados orientados a limitar o condicionar las actividades militares en la zona económica exclusiva se puede incluir a la República Árabe delYemen. Si bien su declaración se refiere en apariencia al derecho de navegación, sus palabras remiten a una implícita autorización para la realización de cualquier actividad o maniobra que intente llevar a cabo un buque de guerra extranjero en aguas bajo su jurisdicción, al afirmar que

...La República Árabe del Yemen se adhiere al concepto del derecho internacional general relativo al libre paso en cuanto se aplica exclusivamente a los buques mercantes y a las aeronaves comerciales. Los buques de propulsión nuclear, así como los buques de guerra y las aeronaves militares en general, deben obtener la autorización previa de la República Árabe del Yemen antes de pasar por sus aguas territoriales, de conformidad con la norma establecida del derecho internacional general relativa a la soberanía nacional.

84 Para un análisis detallado del caso, véase Gómez-Robledo Verduzco, Alonso, Corte Internacional de Justicia. Caso de las actividades militares y paramilitares en Nicaragua y contra Nicaragua. Caso emblemático, México, UNAM, Instituto de Investigaciones Jurídicas, 2011.

85 "Declaraciones y manifestaciones de los Estados parte de la Convención de las Naciones Unidas sobre el Derecho del Mar de 1982”, disponible en: http://www.un.org/Depts/los/con vention_agreements/convention_declarations.htm\#Argentina\%20Upon\%20signature (fecha de consulta: 24 de diciembre de 2016). 
Esta revista forma parte del acervo de la Biblioteca Jurídica Virtual del Instituto de Investigaciones Jurídicas de la UNAM

Entre los Estados alineados en favor de la realización de ejercicios o maniobras militares sin necesidad de notificación ni autorización previa del Estado ribereño se pueden agrupar a Italia y a los Países Bajos. Este último Estado declaró, con respecto a los ejercicios militares en la zona económica exclusiva, que

...La Convención no autoriza al Estado ribereño a prohibir los ejercicios militares en su zona económica exclusiva. Los derechos del Estado ribereño en esa zona están enumerados en el artículo 56 de la Convención, que no le da autoridad en esta materia. En la zona económica exclusiva, todos los Estados gozan de las libertades de navegación y sobrevuelo con sujeción a las disposiciones pertinentes de la Convención.

Finalmente, con el objeto de evitar toda duda a su interpretación, los Países Bajos agregan que “...el Estado ribereño no goza de derechos residuales en la zona económica exclusiva. Los derechos de este en su zona económica exclusiva están enumerados en el artículo 56 de la Convención y no pueden extenderse unilateralmente". ${ }^{86}$

En el caso de la República Argentina, resulta útil señalar la importancia de su declaración y posterior modificación, hipótesis contemplada y habilitada por la propia Convención de 1982, tal y como se observó en la controversia con Ghana por el asunto del buque "ARA Libertad", entre 2012 y 2013, ante un tribunal arbitral conformado según las disposiciones del Anexo VII de la Convención ${ }^{87}$ y que contó con una solicitud de medidas provisionales ante el Tribunal de las Naciones Unidas para el Derecho del Mar. ${ }^{88}$ El fondo de la controversia culminó por acuerdo entre las partes, en septiembre de $2013 .^{89}$

86 Idem

87 The ARA Libertad Arbitration (Argentina v. Ghana), Notice of Arbitration, 29 October 2012.

88 Ésta se presentó en virtud del artículo 290, párrafo 5, de la Convención, con el objeto de obtener la salida de la Fragata ARA Libertad del puerto de Tema y las aguas jurisdiccionales de Ghana.

89 La inmunidad del buque fue confirmada, previamente, por la Suprema Corte de Ghana el 20 de junio de 2013, y su sentencia fue un elemento determinante para el acuerdo final entre las partes. Cfr. The ARA Libertad Arbitration (Argentina v. Ghana), Agreement between Argentina and Ghana, 27 September 2013, disponible en: http: //www.pcacases.com/web/sendAt tach/429 (fecha de consulta: 24 de diciembre de 2016). 
Esta revista forma parte del acervo de la Biblioteca Jurídica Virtual del Instituto de Investigaciones Jurídicas de la UNAM

Tal como se adelantara, Argentina realizó una modificación parcial a su declaración del 18 de octubre de 1995 — depositada el 1o. de diciembre de ese mismo año- con motivo del diseño de su estrategia en el diferendo con Ghana, ampliando la posibilidad de iniciar acciones sin que su propia manifestación le impidiera activar, hipotéticamente y ante petición de Ghana respecto de la incompetencia del tribunal, el mecanismo de solución de controversias de la Convención. ${ }^{90} \mathrm{Al}$ respecto, la República Argentina manifestó que

...in accordance with article 298 of [the] Convention, the Argentine Republic withdraws with immediate effect the optional exceptions to the applicability of section 2 of part XV of the Convention provided for in that article and set forth in its declaration dated 18 October 1995 (deposited on 1 December 1995) to "military activities by government vessels and aircraft engaged in noncommercial service". ${ }^{91}$

En otras palabras, se trató de un retiro parcial, con efecto inmediato, de las excepciones con relación a las "actividades militares de buques y aeronaves de servicio no comercial", manteniendo el resto de las exclusiones sobre las posibles controversias restantes: a) la interpretación o la aplicación de los artículos 15, 74 y 83 de la Convención, concernientes a la delimitación de las zonas marítimas, o las relativas a bahías o títulos históricos; b) actividades militares, aunque habilitando aquellas que versen sobre actividades militares de buques y aeronaves de servicio no comercial, y c) las controversias respecto de las cuales el Consejo de Seguridad de las Naciones Unidas ejerza las funciones que le confiere la Carta.

Por último, cabe destacar las declaraciones de la República Popular China, formuladas en última instancia el 25 de agosto de 2006, por cuanto manifiesta no aceptar los procedimientos previstos en la sección 2 de la parte XV,

90 Este detalle adquiere especial relevancia cuando, como en el caso de estudio, el propio demandado no había realizado declaración alguna con arreglo al artículo 287, y respecto del artículo 298, sólo manifestó, el 15 de diciembre de 2009, excluir las controversias señaladas en el párrafo 1, inciso a. Disponible en: http: / /www.un.org/Depts/los/convention_agreements / convention_declarations.htm\#Argentina\%20Upon\%20signature.

91 "Declaraciones y manifestaciones de los Estados parte de la Convención de las Naciones Unidas sobre el Derecho del Mar de 1982”, disponible en: http://www.un.org/Depts/los/con vention_agreements/convention_declarations.htm\#Argentina\%20Upon\%20signature (fecha de consulta: 24 de diciembre de 2016). 
Esta revista forma parte del acervo de la Biblioteca Jurídica Virtual del Instituto de Investigaciones Jurídicas de la UNAM http://www.juridicas.unam.mx/ https://biblio.juridicas.unam.mx/bjv DOI: http://dx.doi.org/10.22201/iij.24487872e.2018.18.12098

https://revistas.juridicas.unam.mx/

con respecto a las controversias especificadas en el párrafo 1 , incisos $a, b$ y $c$, del artículo 298 de la Convención. Ésta debe adicionarse a la anterior comunicación, formulada al momento de su ratificación, del 7 de junio de 1996:

1. De conformidad con las disposiciones de la Convención de las Naciones Unidas sobre el Derecho del Mar, la República Popular China gozará de derechos de soberanía y jurisdicción sobre una zona económica exclusiva de 200 millas marinas y sobre la plataforma continental.

2. La República Popular China efectuará, mediante consultas, la delimitación de los límites de la jurisdicción marítima con los Estados con costas adyacentes o situadas frente a frente de China, respectivamente, sobre la base del derecho internacional y de conformidad con el principio de equidad.

3. La República Popular China reafirma su soberanía sobre todos sus archipiélagos e islas, tal como se enumeran en el artículo 2 de la Ley de la República Popular China sobre el mar territorial y la zona contigua, que fue promulgada el 25 de febrero de 1992.

4. La República Popular China reafirma que las disposiciones de la Convención de las Naciones Unidas sobre el Derecho del Mar relativas al paso inocente por el mar territorial no menoscabarán el derecho de un Estado ribereño a exigir, de conformidad con sus leyes y reglamentos, a un Estado extranjero que obtenga la aprobación previa del Estado ribereño o le notifique previamente el paso de sus buques de guerra por el mar territorial del Estado ribereño. ${ }^{92}$

Estas declaraciones han revestido un particular interés, a pesar de su resultado infructuoso, en la controversia entre Filipinas y China en el Mar del Sur de China ${ }^{93}$ y cuyo reclamo de fondo fue favorable a las pretensiones del Esta-

92 "Declaraciones y manifestaciones de los Estados parte de la Convención de las Naciones Unidas sobre el Derecho del Mar de 1982", disponible en: http://www.un.org/Depts/los/ convention_agreements/convention_declarations.htm\#China\%20after\%20ratification (fecha de consulta: 26 de diciembre de 2016).

93 El área en disputa, de gran valor geoestratégico, involucra, además, los intereses de China, Taiwán, Vietnam, Filipinas, Malasia y Brunei sobre las islas Paracel, el banco de Scarborough y las islas Spratly, que incluyen los espacios y formaciones marítimas circundantes, de gran valor e influencia geopolítica y económica. Los primeros tres Estados reivindican la totalidad del archipiélago; Filipinas y Malasia, sólo una parte; por otro lado, Brunei no ha realizado reclamo de momento. Al respecto, véanse Brookes, Peter, "China Building Islands with Military Outposts”, Northern Virginia Daily, 14 de abril de 2015, p. 3; Dutton, Peter, Military Activities in the EEZ:A U.S.-China Dialogue on Security and International Law in the Maritime Commons, Newport, 
Esta revista forma parte del acervo de la Biblioteca Jurídica Virtual del Instituto de Investigaciones Jurídicas de la UNAM

do reclamante, según lo decidió el 12 de julio de 2016 un tribunal arbitral conformado con base en las disposiciones del Anexo VII de la Convención de $1982 .{ }^{94}$

El laudo, emitido y con carácter definitivo e inapelable, le dio la razón a Filipinas, al afirmar que China carecía de fundamento legal para reclamar "derechos históricos" en la zona disputada, y que su accionar violó los derechos de soberanía del Estado demandante. China interpretó, y aún sostiene dicho criterio, que el tribunal arbitral carece de jurisdicción y que el laudo, así como sus efectos, son asuntos exceptuados en la Convención de 1982 en virtud de las declaraciones chinas de 2006, ${ }^{95}$ y que corresponde utilizar la solución diplomática, postura que reafirmó al no participar oficialmente en el arbitraje en cuestión. ${ }^{96}$

China Maritime Studies Institute-U.S. Naval War College, 2010; Hong, Nong, Law and Politics in the South China Sea. Assessing the Role of UNCLOS in Ocean Dispute Settlement, Edmonton, University of Alberta, 2010; Keyuan, Zou, China's Marine Legal System and the Law of the Sea, LeidenBoston, Martinus Nijhoff, 2005; Kline, Robert T., "The Pen and the Sword: The People's Republic of China's Effort to Redefine the Exclusive Economic Zone Through Maritime Law Fare and Military Enforcement", Military Law Review, vol. 216, 2013, pp. 122-169; Pedrozo, Raul, "Preserving Navigational Rights and Freedoms: The Right to Conduct Military Activities in China's Exclusive Economic Zone”, Chinese Journal of International Law, vol. 9, núm. 1, 2010, pp. 9-29; Yao-Dong, Yu y Wen-Jin, Piao, "Legal Study on Military Activities in the EEZ: With a Focus on Foreign Military Activities in the EEZ of P. R. China”, KMI International Journal of Maritime Affairs and Fisheries, núm. 3, 2011, pp. 163-181, entre otros.

94 The South China Sea Arbitration (The Republic of Philippines v. The People's Republic of China), Award of 12 July 2016. El caso se origina cuando China, por vía de hecho, intentó fortalecer su posición realizando rellenos de arrecifes y la construcción de islas artificiales para ser utilizadas como asentamientos de faros, pistas aptas para aeronaves y establecer bases militares, oceanográficas y de pesca. Esto motivó que Estados Unidos, actor interesado en la zona, alegara que se trata de espacios regulados para la navegación internacional. En los últimos años, la situación se agravó debido a incidentes que involucraron a buques pesqueros con tripulación armada, establecimientos de plataformas petrolíferas e incursiones de buques de guerra. El tribunal se constituyó y decidió admitir, finalmente, el caso en 2015, a pesar de la negativa China a participar en el proceso.

95 En efecto, China interpreta que la misma excluye el tratamiento de la frontera marítima. Sin embargo, el tribunal arbitral no se refirió a la frontera en sí misma, sino a las alegaciones de Filipinas respecto de acontecimientos en determinados lugares del Mar de China Meridional y que sólo los analizó en la medida de los derechos y las obligaciones de las partes. Cfr. The South China Sea Arbitration (The Republic of Philippines v. The People's Republic of China), Award of 12 July 2016, p. 2, para. 6.

96 Pese a su decisión de no comparecer formalmente en ningún momento del presente procedimiento, China expresó su opinión de manera informal, el 7 de diciembre de 2014, 
Esta revista forma parte del acervo de la Biblioteca Jurídica Virtual del Instituto de Investigaciones Jurídicas de la UNAM http://www.juridicas.unam.mx/ https://biblio.juridicas.unam.mx/bjv

https://revistas.juridicas.unam.mx/

DOI: http://dx.doi.org/10.22201/iij.24487872e.2018.18.12098

Las declaraciones chinas y su interpretación respecto del artículo 298 de la Convención constituyen el pilar de su andamio jurídico en el caso, proyectándose en una perspectiva que intentó limitar la competencia del tribunal arbitral y que se sintetiza en la posición del gobierno chino realizada con anterioridad al laudo definitivo, el 12 de mayo de 2016, por el director general del Departamento de Tratados del Ministerio de Relaciones Exteriores de China, Xu Hong, titulado Briefing on the South China Sea Arbitration Initiated by the Philippines, que afirma: 1) la esencia del asunto es una controversia de soberanía territorial fuera del alcance de la Convención; 2) en caso de que algunos de los reclamos fueran merecedores de interpretación y aplicación de la Convención, constituyen parte integrante de una delimitación marítima que fue excluida del arbitraje obligatorio por China en su Declaración de 2006; 3) toda vez que China y Filipinas han acordado resolver sus disputas en el Mar del Sur de China a través de la negociación, este último Estado se encuentra impedido para iniciar un arbitraje unilateral; 4) Filipinas ha incumplido con la obligación de realizar un intercambio de opiniones previos con China, y 5) el inicio de la acción de Filipinas constituye un abuso. ${ }^{97}$

En esencia, el gobierno de China interpreta que el laudo constituye una opinión "personal" no vinculante de los árbitros, ya que se encuentra convencido que el tribunal arbitral carece de jurisdicción. ${ }^{98}$

mediante un documento del Ministerio de Relaciones Exteriores de China titulado "China's Position Paper”, argumentando que el tribunal carecía de jurisdicción para examinar cualquiera de las solicitudes de Filipinas, con fundamento en: a) la esencia del objeto del arbitraje y sus características marítimas; $b$ ) el acuerdo entre las partes de resolver sus controversias mediante negociación, y c) que la solicitud filipina constituye, en esencia, una delimitación marítima entre las partes. Por otro lado, el embajador de China en los Países Bajos envió comunicaciones a los miembros del Tribunal, a título individual, y aclaró que no debían ser interpretadas como participación en el procedimiento. En su laudo de admisibilidad, emitido el 29 de octubre de 2015, el tribunal arbitral se abocó sobre siete de las quince solicitudes de Filipinas, aplazando las restantes para el fondo.

97 The South China Sea Arbitration (The Republic of Philippines v. The People's Republic of China), Award of 12 July 2016, pp. 33 y 34, para. 96.

98 Ibidem, p. 34, para. 97. A futuro surgen dos posibles consecuencias: 1) la aceptación del laudo por parte del gobierno de Pekín, o 2) el rechazo, que parece probable a tenor del enérgico desconocimiento chino. Ello podría, en un supuesto extremo, poner en peligro la paz y la seguridad internacionales en la región. Si bien China posee un asiento permanente en el Consejo de Seguridad de la ONU y cuenta con un poder de veto, cabe señalar la existencia de la Resolución 377 de la Asamblea General, conocida como Unión Pro Paz, que le permite a 
Esta revista forma parte del acervo de la Biblioteca Jurídica Virtual del Instituto de Investigaciones Jurídicas de la UNAM

En cuanto a las declaraciones chinas al artículo 298 de la Convención, el tribunal arbitral analizó las mismas, incluyendo las objeciones a la disputa de soberanía de las islas y la delimitación marítima, en razón de las manifestaciones de 2006. ${ }^{99}$ El tribunal arbitral advirtió la existencia de controversia de soberanía sobre las islas, aunque el asunto sometido a arbitraje no se refiere a éstas en ese sentido, destacando que Filipinas

“... has not asked the Tribunal to rule on sovereignty and, indeed, has expressly and repeatedly requested that the Tribunal refrain from so doing." The Tribunal emphasised that it did "not see that any of the Philippines' Submissions require an implicit determination of sovereignty." Finally, the Tribunal observed that it was "fully conscious of the limits on the claims submitted to it and, to the extent that it reaches the merits of any of the Philippines' Submissions, intends to ensure that its decision neither advances nor detracts from either Party's claims to land sovereignty in the South China Sea."

With respect to the latter objection, the Tribunal noted that a dispute concerning whether a State possesses an entitlement to a maritime zone is a distinct matter from the delimitation of maritime zones in an area in which they overlap. While a wide variety of issues are commonly considered in the course of delimiting a maritime boundary, it does not follow that a dispute over each of these issues is necessarily a dispute over boundary delimitation. ${ }^{100}$

En consecuencia, el tribunal arbitral confirmó que la solicitud filipina no se encuentra sujeta a las excepciones de la Convención, agregando que

Turning to the matters raised in the Philippines' Submissions, the Tribunal reviewed the record to determine whether disputes existed between the Parties at the time the Philippines commenced this arbitration and whether such disputes

este último órgano recomendar a los miembros de la ONU la adopción de medidas colectivas en caso de inoperancia del Consejo de Seguridad, como consecuencia del voto negativo de un miembro permanente, de modo que produzca una amenaza para la paz, un quebrantamiento de la paz o un acto de agresión. Un análisis más profundo de estas posibilidades merece un estudio por separado. Para el tratamiento de esta cuestión, véase Arredondo, Ricardo, Intervención humanitaria y responsabilidad de proteger. ¿Hacia un nuevo paradigma de protección de los derechos humanos?, Buenos Aires, Catálogos, 2012, pp. 144 y ss.

99 The South China Sea Arbitration (The Republic of Philippines v. The People's Republic of China), Award of 12 July 2016, p. 58, para. 153.

100 Ibidem, pp. 58 y 59, paras. 154 y 155. 
Esta revista forma parte del acervo de la Biblioteca Jurídica Virtual del Instituto de Investigaciones Jurídicas de la UNAM http://www.juridicas.unam.mx/ https://biblio.juridicas.unam.mx/bjv

https://revistas.juridicas.unam.mx/

DOI: http://dx.doi.org/10.22201/iij.24487872e.2018.18.12098

concerned the interpretation and application of the Convention. In so doing, the Tribunal noted that it was necessary to address some ambiguity regarding China's position on the matters before it and recalled that the existence of a dispute may be inferred from the conduct of a State, or from silence, and is a matter to be determined objectively. The Tribunal considered that each of the Philippines' claims reflected a dispute concerning the Convention and noted in particular that a dispute concerning the interaction between the Convention and other rights (including any Chinese historic rights) is a dispute concerning the Convention. ${ }^{101}$

El tribunal arbitral realizó, además, un análisis exhaustivo de las limitaciones a su competencia que disponen los artículos 297 y 298, a la luz de las declaraciones chinas del 25 de agosto de 2006. Al respecto, el tribunal reconoció que la aplicabilidad de estas restricciones y excepciones podían condicionar ciertos aspectos de la solicitud de Filipinas:

(a) First, the Tribunal noted that its jurisdiction may depend on the nature and validity of any claim by China to historic rights in the South China Sea and whether such rights are covered by the exclusion from jurisdiction of "historic bays or titles."

(b) Second, the Tribunal noted that its jurisdiction may depend on the status of certain maritime features in the South China Sea and whether the Philippines and China possess overlapping entitlements to maritime zones in the South China Sea. If so, the Tribunal may not be able to reach the merits of certain claims because they would first require a delimitation of the overlapping zones (which the Tribunal is not empowered to do).

(c) Third, the Tribunal noted that its jurisdiction may depend on the maritime zone in which alleged Chinese law enforcement activities in fact took place.

(d) Fourth, the Tribunal noted that its jurisdiction may depend on whether certain Chinese activities are military in nature. ${ }^{102}$

Luego de abordar la primera excepción china a la jurisdicción planteada como artículo 298, párrafo 1 , inciso a, subinciso $i$, de la Convención, el tribunal arbitral rechazó la misma con fundamento en que la controversia no trataba — simplemente— sobre la delimitación marítima debido, entre

101 Ibidem, pp. 59 y 60, paras. 155 y 156.

102 Ibidem, p. 62, para. 162. Este último aspecto, referido a la naturaleza de las actividades chinas como "militares", fue señalado en el laudo de admisibilidad del 29 de octubre de 2015 y postergado para un tratamiento en el fondo del asunto. Ibidem, pp. 139 y 140, paras. 394-396. 
Esta revista forma parte del acervo de la Biblioteca Jurídica Virtual del Instituto de Investigaciones Jurídicas de la UNAM

otras razones, a la ausencia de una necesaria superposición de derechos. ${ }^{103}$ Con relación a la segunda excepción, aplicable a las controversias que involucran bahías o títulos históricos, el tribunal señaló que el Mar del Sur de China no constituye geográficamente una bahía y que la cuestión era determinar la existencia — O no_- de una reivindicación de títulos históricos en la zona por parte de China, junto con su alcance que, en caso de confirmarse, habilitaría el examen de la jurisdicción del tribunal. ${ }^{104}$ En sus propias palabras, el tribunal arbitral concluyó que “... In the absence of any possible overlap, there is quite literally nothing to delimit”. ${ }^{105}$

Asimismo, el tribunal arbitral declaró la inexistencia de argumentos jurídicos para los derechos históricos o derechos de soberanía chinos, más allá de lo establecido en la Convención, en las aguas del Mar de China Meridional dentro de la denominada línea de los nueve puntos. ${ }^{106}$ El tribunal no observó pruebas de derechos históricos de China, preexistentes a la Convención de 1982, con relación al uso exclusivo de recursos vivos y no vivos en el área señalada, descartando, además, la utilización de la línea de los nueve puntos como fundamento del supuesto derecho chino respecto de Mischief Reef o Second Thomas Shoal, por lo que rechazó la hipótesis de derechos superpuestos y concluyó que

...it follows that there exists no legal basis for any entitlement by China to maritime zones in the area of Mischief Reef or Second Thomas Shoal. Accordingly, there is no situation of overlapping entitlements that would call for the application of Articles 15, 74, or 83 to delimit the overlap. Because no delimitation is required

103 Ibidem, p. 85, paras. 203 y 204. Específicamente, el tribunal arbitral afirmó que era necesario determinar el carácter de "isla" de Spratly, en el sentido del artículo 121 de la Convención, y los espacios marítimos que se proyectarían de confirmarse este carácter, generando una superposición de derechos entre las partes, que impide el análisis posterior del tribunal, a tenor de la declaración china al artículo 298. Ibidem, p. 255, para. 628.

104 Ibidem, pp. 85 y 86, para. 205. Para ello, el tribunal arbitral consideró necesario analizar los reclamos de China en el Mar de China Meridional más allá de su reclamo de soberanía sobre las islas y sus espacios marítimos adyacentes, a fin de determinar, finalmente, si las mismas equivalen a un "título histórico". Ibidem, p. 86, para. 206.

105 Ibidem, p. 225, para. 629.

106 Se trata de una línea de demarcación realizada por China en forma de "U", que representa en su interior el territorio marítimo insular que este Estado reclama como propio y comprende, en la práctica, la mayor parte del Mar del Sur de China. Disponible en: http: / / www. lavanguardia.com/internacional/20160712/403140497411/tribunal-arbitraje-razon-filipi nas-disputa-martima-mar-china-meridional.html (fecha de consulta: 31 de diciembre de 2016). 
Esta revista forma parte del acervo de la Biblioteca Jurídica Virtual del Instituto de Investigaciones Jurídicas de la UNAM http://www.juridicas.unam.mx/ https://biblio.juridicas.unam.mx/bjv

https://revistas.juridicas.unam.mx/

DOI: http://dx.doi.org/10.22201/iij.24487872e.2018.18.12098

—or, indeed, even possible — there is no possible basis for the application of the exception to jurisdiction in Article 298 (1) (a) (i). ${ }^{107}$

En relación con las actividades de construcción chinas ${ }^{108}$ y su posible excepción como actividad militar en el artículo 298, párrafo 1, inciso b, Filipinas argumentó que aquéllas no fueron invocadas como tales por China y que el propio gobierno chino caracterizó, repetidamente, el establecimiento de estas islas artificiales con un propósito civil. Asimismo, Filipinas agregó que de presentarse una finalidad mixta cívico-militar, esta situación no está comprendida específicamente dentro de la excepción de actividades militares. ${ }^{109} \mathrm{Al}$ respecto, el tribunal arbitral sostuvo lo siguiente:

The Tribunal likewise held that the other possible exceptions in Article 298 of the Convention posed no bar to its jurisdiction... The harmful fishing and harvesting practices complained of in the Submission as originally formulated have no connection with "military activities". To the extent the incidents could be characterised as related to "law enforcement activities", the Tribunal pointed out that the law enforcement activities exception in Article 298 (1) (b) would not in any event apply.

...Second, although the status of Second Thomas Shoal and the question of whether the feature was potentially within the entitlement of either China or the Philippines to an exclusive economic zone were undetermined at the time of the Award on Jurisdiction, the Tribunal noted that Article 297 (1) (c) expressly reaffirms the availability of compulsory dispute settlement for disputes concerning

107 The South China Sea Arbitration (The Republic of Philippines v. The People's Republic of China), Award of 12 July 2016, pp. 225, 226, 256 y 278, paras. 631, 633, 694 y 695. Asimismo, el tribunal arbitral decidió que las disposiciones de los artículos 297, párrafo 3, inciso a, y 298, párrafo 1 , inciso $b$, sólo limitan la solución obligatoria de controversias en caso de ejercicios de derechos soberanos en relación con los recursos vivos situados en la zona económica exclusiva; pero las mismas no resultan aplicables cuando un Estado alega la violación de la zona económica exclusiva de otro Estado. Por lo tanto, el tribunal arbitral concluye que tiene jurisdicción. Ibidem, p. 279, para. 695.

108 De existencia probada por Filipinas mediante documentos anexos a su solicitud, presentada como prueba documental: Armed Forces of the Philippines, Chronology of Events in the Kalayaan Island Group (2004) (Anexo 53); Armed Forces of the Philippines, Chronological Development of Artificial Structures on Features (Anexo 96); "Matrix of Events" documents compiled by the Armed Forces of the Philippines for Cuarteron, Gaven, Fiery Cross, Johnson, and Subi Reefs (Anexos 86-91), y Memorial, paras. 5.68-5.75. Ibidem, pp. 371 y 372, para. 933, nota 1086.

109 Ibidem, p. 356, para. 893. Idénticos argumentos se observan en p. 404, paras. 1011 y 1012 . 
Esta revista forma parte del acervo de la Biblioteca Jurídica Virtual del Instituto de Investigaciones Jurídicas de la UNAM

"alleged violations of international rules and standards for the protection and preservation of the marine environment." The Tribunal's decision in this Award that Second Thomas Shoal is a low-tide elevation located in an area that can only form part of the exclusive economic zone of the Philippines... further confirms that the law enforcement exception in Article 298 (1) (b) has no application in these circumstances. ${ }^{110}$

En consecuencia, el tribunal arbitral decidió analizar la posible exclusión fundada en razón de las actividades militares de acuerdo con la particular actividad china en Mischief Reef, con el objeto de determinar si revestían naturaleza militar. ${ }^{111} \mathrm{Al}$ respecto, el tribunal arbitral tomó nota de las reiteradas declaraciones de China en cuanto a que las acciones de construcción de islas por ella emprendida revisten carácter civil y no una finalidad militar, para concluir, por tanto, que no consideraría a las actividades como militares y que, en definitiva, su conducta no se encuentra contemplada en el artículo 298, párrafo 1 , inciso $b .{ }^{112}$

Asimismo, el tribunal arbitral consideró los incidentes en relación con las actividades chinas en los alrededores de Second Thomas Shoal y su interacción con las fuerzas militares de Filipinas. Al respecto, este tribunal concluyó que la Second Thomas Shoal es una elevación en bajamar que no genera espacios marítimos propios, de acuerdo con el artículo 212 de la Convención, y que, en consecuencia, China carecía de fundamentos jurídicos para emprender acciones en esta área. Sin embargo, el tribunal arbitral analizó el planteo filipino respecto de la ausencia de solicitud de aplicación, por parte de China, del artículo 298 a estas acciones y afirmó que

First, the Philippines argues that "[ $\mathrm{t}]$ he decision to rely on those options is a matter of choice, both at the declaration stage and thereafter. A respondent is not required to insist on a jurisdiction exception covered by a declaration."'The Tribunal unders-

110 Ibidem, pp. 370 y 371, paras. 928 y 930.

111 Ibidem, p. 371, para. 932.

112 En palabras del tribunal arbitral: "The Tribunal will not deem activities to be military in nature when China itself has consistently and officially resisted such classifications and affirmed the opposite at the highest levels. Accordingly, the Tribunal accepts China's repeatedly affirmed position that civilian use compromises the primary (if not the only) motivation underlying the extensive construction activities on the seven reefs in the Spratly Islands. As civilian activity, the Tribunal notes that China's conduct falls outside the scope of Article 298(1)(b)...”. Ibidem, pp. 372, 373 y 413, paras. 937, 938 y 1028. 
Esta revista forma parte del acervo de la Biblioteca Jurídica Virtual del Instituto de Investigaciones Jurídicas de la UNAM http://www.juridicas.unam.mx/ https://biblio.juridicas.unam.mx/bjv

https://revistas.juridicas.unam.mx/

DOI: http://dx.doi.org/10.22201/iij.24487872e.2018.18.12098

tands the Philippines' position to be that if China has not specifically invoked Article 298(1)(b) in the course of these proceedings, the Tribunal need look no further into the application of this provision. The Tribunal, however, cannot agree with this proposition. Article 298(1) provides for a State Party to "declare in writing that it does not accept" a form of compulsory dispute resolution with respect to one or more of the enumerated categories of disputes. This formulation stands in stark contrast to the more optional formulation employed in Article 297(2) and 297(3), which provide that a State Party "shall not be obliged to accept the submission" of a dispute to compulsory settlement. In contrast to an objection under Article 297, the Tribunal sees nothing to suggest that a provision of Article 298(1) must be specifically invoked. Once made, a declaration under Article 298(1) excludes the consent of the declaring State to compulsory settlement with respect to the specified categories of disputes. Article 299(1) then expressly provides in unequivocal terms that "[a] dispute... excepted by a declaration made under article 298 from the dispute settlement procedures provided for in section 2 may be submitted to such procedures only by agreement of the parties to the dispute." Such a declaration stands until modified or withdrawn. The absence of any mention of Article 298(1)(b) from China's Position Paper and public statements does not obviate the Tribunal's need to consider the applicability of this provision. ${ }^{113}$

Sobre este punto _ el último en nuestro tema de interés_-, el tribunal arbitral decide que, respecto a las acciones producidas en Second Thomas Shoal, las actividades de los buques chinos son calificadas como "militares", razón por la cual el tribunal concluye que carece de jurisdicción sobre éstas. En palabras del tribunal:

On the basis of the record set out above, the Tribunal finds that the essential facts at Second Thomas Shoal concern the deployment of a detachment of the Philippines' armed forces that is engaged in a stand-off with a combination of ships from China's Navy and from China's Coast Guard and other government agencies. In connection with this stand-off, Chinese Government vessels have attempted to prevent the resupply and rotation of the Philippine troops on at least two occasions. Although, as far as the Tribunal is aware, these vessels were not military vessels, China's military vessels have been reported to have been in the vicinity. In the Tribunal's view, this represents a quintessentially military situation, involving the military forces of one side and a combination of military and paramilitary forces on the other, arrayed in

113 Ibidem, pp. 453-455, paras. 1153-1156. 
Esta revista forma parte del acervo de la Biblioteca Jurídica Virtual del Instituto de Investigaciones Jurídicas de la UNAM

opposition to one another. As these facts fall well within the exception, the Tribunal does not consider it necessary to explore the outer bounds of what would or would not constitute military activities for the purposes of Article 298(1)(b).

Accordingly, the Tribunal finds that it lacks jurisdiction to consider the Philippines Submissions No. 14(a) to (c). ${ }^{114}$

\section{CONCLUSIÓN}

En el presente trabajo, hemos demostrado la importancia que tiene la utilización de las declaraciones de los Estados en los tratados multilaterales, así como las particularidades que presentan las declaraciones interpretativas, con especial aplicación a las controversias más recientes sobre la utilización de los mares y océanos.

Durante el desarrollo del mismo, advertimos que las declaraciones y las declaraciones interpretativas, en una relación género-especie, poseen un innegable carácter de acto unilateral que debe cumplir con las condiciones establecidas por el derecho internacional, convencional ${ }^{115}$ y consuetudinario, y que además no deben implicar una violación a una norma de ius cogens. Asimismo, hemos señalado la necesaria distinción que, en algunas ocasiones, presentan las denominadas "declaraciones condicionales" y las reservas, sugiriendo que su debate resulta, por lo menos, considerable. Sin embargo, una afirmación es concluyente en nuestro estudio: las declaraciones interpretativas deben formularse de acuerdo con el derecho internacional consuetudinario - en lo general y sin afectar una norma de ius cogens - y acatar especialmente el objeto y fin del tratado. ${ }^{116}$

114 Ibidem, p. 456, paras. 1161 y 1162.

115 Walker, George K., 'Professionals' definitions and States' Interpretative Declarations (Understandings, Statements, or Declarations) for the 1982 Law of the Sea Convention”, Emory International Law Review, vol. 21, 2007, pp. 539 y ss. Sin embargo, este criterio no resulta unánime en la doctrina especializada y se ha sostenido que las declaraciones interpretativas son reguladas por el derecho de los tratados y no por la costumbre. Cfr. Naime S. Henkel, Monica Y., "El final de la espiral del caos: la regulación de los actos jurídicos unilaterales de los Estados", Anuario Mexicano de Derecho Internacional, vol. XII, 2012, p. 637.

116 Para un análisis del objeto y fin de los tratados, véase Klabbers, Jan, “Treaties, Object and Purpose”, en Wolfrum, Rüdiger (ed.), The Max Planck Encyclopedia of Public International Law, Oxford, Oxford University Press, 2012. En relación con los efectos jurídicos de las 
Esta revista forma parte del acervo de la Biblioteca Jurídica Virtual del Instituto de Investigaciones Jurídicas de la UNAM

Una extralimitación del Estado declarante, en contra de una norma imperativa del derecho internacional o formulada más allá de lo autorizado en el tratado - e incluso, si se quiere, de modo que pueda ser entendida como una modificación del objeto y fin del mismo-, nos permite sostener que su consecuencia resulta, respectivamente, en: a) anular totalmente sus efectos, en especial cuando se trata de normas de ius cogens, tal y como lo prevé el artículo 53 de la Convención de Viena sobre el Derecho de los Tratados de 1969, o b) limitar aquellos en circunstancias determinadas. Esto podría ser explicitado con algún ejemplo.

La particular importancia de las declaraciones interpretativas representa un fenómeno que materializa una verdad evidente: los Estados consideran que la manifestación de su consentimiento en obligarse por un tratado multilateral puede acompañarse, desde tiempos inmemoriales, por declaraciones unilaterales, en virtud de las cuales indican el espíritu con el que convienen, adhieren o aceptan ratificar internacionalmente el mismo, sin que ello implique modificar o excluir los efectos jurídicos de incuestionables disposiciones de un tratado. A esta idea se le puede adicionar la facultad inherente de modificar las declaraciones, tal y como ha quedado evidente en la actitud lícita de la República Argentina en el caso ARA Libertad.

En cuanto a las declaraciones unilaterales formuladas con relación a la Convención de 1982 y las opciones que presenta, en virtud de una cláusula de opción respecto de los artículos 287 y 298, junto a la habilitación de declaraciones interpretativas con el alcance del artículo 309 del propio tratado, se advierte la inadmisibilidad de actos unilaterales que presenten naturaleza de reserva prohibida convencionalmente y que, igualmente, resulta imposible de defender no sólo respecto de los intereses jurídicos tutelados en la misma y que afecta a los intereses de todas las demás partes del tratado, sino también por el espíritu de su negociación y el esfuerzo de la comunidad internacional para acordar sus disposiciones.

Sin embargo, la autorización de declaraciones interpretativas en la Convención, de modo que el Estado —u organización internacional pertinen-

reservas, Pellet afirma que el artículo 21 de las convenciones de Viena de 1969, 1978 y 1986 realiza una mínima contribución al esclarecimiento de los efectos que produciría una reserva inválida, razón por la que se dedica a su estudio en el punto 4.3 de la Guía. Quien fuera el relator especial a cargo de su elaboración dedicó su atención a las posibles consecuencias de una objeción, admitiendo, eventualmente, un "equilibrio consensual" (consensual balance) entre el reservante y el objetor, como una especie de "contrarreserva”, a la cual el primero puede formular una “contraobjeción”. Cfr. Pellet, Alain, op. cit., pp. 1090 y 1091. 
Esta revista forma parte del acervo de la Biblioteca Jurídica Virtual del Instituto de Investigaciones Jurídicas de la UNAM

te- indique la manera en que lo aplicará internamente, sin afectar sus propios derechos y obligaciones ni los correlativos de las demás partes, presenta dos potenciales particularidades: 1) un supuesto de declaración interpretativa con un sentido idéntico entre dos o más partes de la Convención, o formulada por uno y aceptada expresamente por otro, constituye una interpretación auténtica de la norma, al menos entre los declarantes en cuestión, sin afectar la interpretación de otras partes, y 2) la generación de una eventual costumbre bilateral, regional o internacional, según el caso, como consecuencia de la práctica interna y ante la influencia gradual de las declaraciones interpretativas.

Al margen de lo anterior es habitual que los Estados formulen "declaraciones" con aparente fin interpretativo que, en realidad, constituyen reservas. La Convención de 1982 no es ajena a esta situación y su uso ha merecido, en más de una declaración, la protesta de Estados parte que se encuentran atentos a este tipo de artimañas y distracciones de consecuencias abusivas. ${ }^{117}$ No obstante, es posible que una "declaración" pueda ser considerada como una "reserva", y viceversa, total o parcialmente, por algunos Estados u organizaciones.

En razón de lo expuesto, cabe concluir que las declaraciones interpretativas constituyen actos unilaterales formulados con el objeto de interpretar, aclarar o dilucidar el tratado o alguna de sus disposiciones. Si bien comparten con las reservas esa naturaleza unilateral — estas últimas pueden ser pasibles de objeciones, objeciones indubitadas o ser consentidas expresa y tácitamente, según los casos previstos en las convenciones de Viena de 1969, 1978 y 1986 - , podemos destacar que las declaraciones interpretativas, en caso de ser consideradas como tales, logran ser objeto de una reacción de aprobación o acuerdo por parte de Estados u organismos internacionales con interés en la misma, de manera similar a la que podrían también oponerse, sin perjuicio de lo señalado por el artículo 31, párrafo 3, inciso $a$, de las convenciones de Viena señaladas.

Esta última hipótesis se presenta, a su vez, respecto de la Convención de 1982 ante la prudente oposición o preocupación de algunos Estados como reacción a las declaraciones formuladas de conformidad con los artículos

117 Con acierto, Wood destaca la importancia del consentimiento tanto respecto de las reservas como de las declaraciones interpretativas, al afirmar que "The question of reservations and interpretative declarations is part of the law of treaties, in which the principle of consent is paramount”. Cfr. Wood, Michael, op. cit., p. 1102. 
Esta revista forma parte del acervo de la Biblioteca Jurídica Virtual del Instituto de Investigaciones Jurídicas de la UNAM http://www.juridicas.unam.mx/ https://biblio.juridicas.unam.mx/bjv https://revistas.juridicas.unam.mx/ DOI: http://dx.doi.org/10.22201/iij.24487872e.2018.18.12098

309 y 310, destacándose entre ellas las objeciones italianas — formuladas el 24 de noviembre de 1995- a las declaraciones de Brasil, Cabo Verde, India y Uruguay:

...Italia desea reiterar la declaración que hizo en el momento de firmar la Convención y que confirmó en el momento de ratificarla, según la cual "los derechos del Estado ribereño en esa zona no incluyen el de que se le notifiquen los ejercicios o maniobras militares ni el de autorizarlos". Con arreglo a la declaración hecha por Italia en el momento de ratificar la Convención, esta declaración constituye la respuesta a todas las declaraciones anteriores y futuras de otros Estados relativas a las cuestiones a que se refiere. ${ }^{118}$

Entre otros ejemplos, podemos mencionar a la reacción de Túnez, del 22 de febrero de 1994, con relación a la declaración interpretativa de Malta, por cuanto este primer Estado manifestó que

...Según la interpretación de los artículos 74 y 83 de la Convención que se hace en esa declaración, de no haber acuerdo sobre la delimitación de la zona económica exclusiva, la plataforma continental u otras zonas marítimas, para lograr una solución equitativa, la frontera debe establecerse en la línea media, es decir, una línea cuyos puntos sean equidistantes de los puntos más próximos de las líneas de base a partir de las cuales se mida la anchura de las aguas territoriales.

El Gobierno de Túnez estima que esa interpretación no es compatible en absoluto con el espíritu y la letra de las disposiciones de esos artículos, que no estipulan la aplicación automática de la línea media para la delimitación de la zona económica exclusiva o la plataforma continental. ${ }^{119}$

La solución a los inconvenientes que presentan el uso de las declaraciones en general y las declaraciones interpretativas como especie se encuentra, como no podría ser de otra manera, en los principios y criterios del derecho internacional consuetudinario, codificado en las convenciones de Viena

118 Disponible en: http://www.wipo.int/wipolex/es/other_treaties/details_notes.jsp?treaty_id= 291 (fecha de consulta: 4 de enero de 2017).

119 Asimismo, es necesario señalar las distintas reacciones que mereció la "declaración interpretativa” de Filipinas por parte de Bielorrusia, Bulgaria, Ucrania y la Federación de Rusia, quienes, entre otros Estados, consideraron aquélla como una reserva a la Convención carente de todo valor o efecto jurídico. Idem. 
Esta revista forma parte del acervo de la Biblioteca Jurídica Virtual del Instituto de Investigaciones Jurídicas de la UNAM

sobre el Derecho de los Tratados de 1969, 1978 y 1986, que establecen una regla general de interpretación y disponen de medios complementarios para superar las dificultades interpretativas, sin olvidar el principio de la buena fe, que excluye toda argucia o interpretación subjetiva maliciosa y la necesidad de obtener una hermenéutica sistemática que recoja el sentido y alcance de la disposición cuestionada dentro del contexto del tratado, de modo que comprenda no sólo su conjunto, sino el preámbulo y sus anexos, así como todo acuerdo que se refiera al mismo y que haya sido concertado por todas las partes interesadas, ${ }^{120}$ sin perder de vista el “entorno normativo". ${ }^{121}$

En todo caso, coincidimos al respecto con Marco Benatar, por cuanto resulta evidente que las declaraciones interpretativas no pueden simplemente ignorarse. Por supuesto, una declaración insignificante tiene poca relevancia o incidencia de modo que provoque una potencial controversia, mientras que en un "nivel intermedio" se pueden encontrar aquellas que no obligan a otros Estados a compartir su interpretación, aunque limitan solamente al declarante frente a una eventual situación de estoppel. Sin embargo, una mayor gravedad poseen las manifestaciones que requieren de cierto acatamiento por parte de otros contratantes, especialmente las que se presenten con intenciones de conformar una costumbre en un futuro, con altas probabilidades de controversia respecto de quienes no compartan la interpretación en cuestión. Por último, el estadio más fortalecido resulta ser la interpretación auténtica, en el que su grado de conflictividad resulta bajo, aunque requiere el acuerdo sobre la interpretación de la declaración entre las partes de la Convención. ${ }^{122}$

Para concluir, es posible afirmar que un tema clásico como el de las declaraciones interpretativas resulta — paradójicamente- siempre vigente debido a la dinámica que presentan las relaciones internacionales y los cambiantes intereses de los Estados que impactan, las más de las veces, en las convenciones multilaterales para influir en éstas mediante manifestaciones unilaterales. Su importancia resulta vital en algunos casos, tal y como lo ha

120 Casado Raigón, Rafael, op. cit., pp. 192 y 193.

121 CDI, Fragmentación del derecho internacional: dificultades derivadas de la diversificación y expansión del derecho internacional, Informe del Grupo de Estudio de la Comisión de Derecho Internacional, elaborado por Martti Koskenniemi, 13 de abril de 2006, pp. 238 y ss. (A/ CN.4/L.682).

122 Benatar, Marco, "From Probative Value to Authentic Interpretation: The Legal Effects of Interpretative Declarations”, Revue Belge de Droit International, núm. 44, 2011-2012, p. 196. 
Esta revista forma parte del acervo de la Biblioteca Jurídica Virtual del Instituto de Investigaciones Jurídicas de la UNAM

demostrado el propio sistema de solución de controversias de la Convención de las Naciones Unidas sobre el Derecho del Mar en asuntos recientes y de indudable valor, como el caso del Mar del Sur de China, que hemos analizado siguiendo el objetivo propuesto, con especial énfasis en las declaraciones formuladas en virtud del artículo 298 y las actividades militares.

VII. BIBLIOGRAFÍA

ARREDONDO, Ricardo, Intervención humanitaria y responsabilidad de proteger. ¿Hacia un nuevo paradigma de protección de los derechos humanos?, Buenos Aires, Catálogos, 2012.

BARberis, Julio A., Formación del derecho internacional, Buenos Aires, Ábaco de Rodolfo Depalma, 1994.

Barberis, Julio A., Fuentes del derecho internacional, La Plata, Platense, 1973.

Benatar, Marco, "From Probative Value to Authentic Interpretation: The Legal Effects of Interpretative Declarations", Revue Belge de Droit International, núm. 44, 2011-2012.

Brookes, Peter, "China Building Islands with Military Outposts", Northern Virginia Daily, 14 de abril de 2015, p. 3.

Bull, Hedley, "Sea Power and Political Influence", Power at Sea I: The New Environment - Adelphi Paper 16, núm. 122, 1976.

CAMERON, Iain, “Treaties, Declarations of Interpretation”, en Wolfrum, Rüdiger (ed.), The Max Planck Encyclopedia of Public International Law, Oxford, Oxford University Press, 2012.

Casado Raigón, Rafael, Derecho internacional, 2a. ed., Madrid, Tecnos, 2015.

CDI, Fragmentación del derecho internacional: dificultades derivadas de la diversificación y expansión del derecho internacional, Informe del Grupo de Estudio de la Comisión de Derecho Internacional, elaborado por Martti Koskenniemi, 13 de abril de 2006 (A/CN.4/L.682).

CDI, Informe de la Comisión de Derecho Internacional, 55o. periodo de sesiones, Octavo informe del señor Alain Pellet, relator especial sobre las reservas a los tratados, 27 de mayo y 10 de julio de 2003, Nueva York, Naciones Unidas, 2003 (A/CN.4/535 y Add.1). 
Esta revista forma parte del acervo de la Biblioteca Jurídica Virtual del Instituto de Investigaciones Jurídicas de la UNAM

CDI, Informe de la Comisión de Derecho Internacional, 63o. periodo de sesiones, 26 de abril-3 de junio de 2011 y 4 de julio-12 de agosto de 2011, Nueva York, Naciones Unidas, 2011 (A/66/10/Add.1).

DEVIDAL, Pierrick, "Reservations, Human Rights Treaties in the 21 st Century: From Universality to Integrity", LLMTheses and Essays - University of Georgia School of Law, Paper 10, 2003.

Diez De Velasco Vallejo, Manuel, Instituciones de derecho internacional público, 18a. ed., Madrid, Tecnos, 2013.

DÖRR, Oliver, "Declaration”, en Wolfrum, Rüdiger (ed.), The Max Planck Encyclopedia of Public International Law, Oxford, Oxford University Press, 2012.

DutTon, Peter, Military Activities in the EEZ: a U.S.-China Dialogue on Security and International Law in the Maritime Commons, Newport, China Maritime Studies Institute-U.S. Naval War College, 2010.

FERnÁNDEZ DE CASADEVANTE Romani, Carlos, Sovereignty and Interpretation of International Norms, Berlín-Heidelberg-Nueva York, Springer, 2007.

Fitzmaurice, Malgosia, “Treaties”, en Wolfrum, Rüdiger (ed.), The Max Planck Encyclopedia of Public International Law, Oxford, Oxford University Press, 2012.

Godio, Leopoldo M. A., "El asunto del Arctic Sunrise y el sistema de solución de controversias de la Convención de Naciones Unidas sobre el Derecho del Mar”, elDial.com, Buenos Aires, 12 de diciembre de 2013.

Godio, Leopoldo M. A., "La Convención de las Naciones Unidas sobre el Derecho del Mar de 1982 y las actividades militares", Revista de la Facultad de Derecho, Universidad de la República, núm. 39, julio-diciembre de 2015.

Godio, Leopoldo M. A. y Rosenthal, Julián M., "The Prompt Release of Vessels in Provisional Measures Procedures. New Trends and Challenges?”, Revista Tribuna Internacional, vol. 4, núm. 7, 2015.

Gómez-Robledo Verduzco, Alonso, Corte Internacional de Justicia. Caso de las actividades militares y paramilitares en Nicaragua y contra Nicaragua. Caso emblemático, México, UNAM, Instituto de Investigaciones Jurídicas, 2011.

GuARDiA, Ernesto de la, Derecho de los tratados internacionales, Buenos Aires, Ábaco de Rodolfo de Palma, 1997.

Guerrero Peniche, Nicolás y Rodríguez Cedeño, Víctor, "Los actos unilaterales de los Estados en derecho internacional: los trabajos de co- 
Esta revista forma parte del acervo de la Biblioteca Jurídica Virtual del Instituto de Investigaciones Jurídicas de la UNAM

dificación en la Comisión de Derecho Internacional", Anuario Mexicano de Derecho Internacional, vol. III, 2003.

Guilfoyle, Douglas y Miles, Cameron A., "Provisional Measures and the MV Arctic Sunrise”, American Journal of International Law, vol. 108, núm. 2, 2014.

Hong, Nong, Law and Politics in the South China Sea.Assessing the Role of UNCLOS in Ocean Dispute Settlement, Edmonton, University of Alberta, 2010. ILC, "Guiding Principles Applicable to Unilateral Declarations of States Capable of Creating Legal Obligations, with Commentaries Thereto”, Yearbook of the International Law Commission 2006, vol. II, Part Two (Doc. A/61/10), 2006.

ILC, "Law of Treaties. Fifth Report by Sir Gerald Fitzmaurice, Special Rapporteur”, Yearbook of the International Law Commission 1960, vol. II, 1960. JANIS, Mark W., "Dispute Settlement in the Law of the Sea Convention: The Military Activities Exception”, Ocean Development \& International Law, vol. 4, núm. 1, 1977.

Keohane, Robert y Nye, Joseph, Poder e interdependencia. La política mundial en transición, Buenos Aires, GEL, 1988.

Keyuan, Zou, China's Marine Legal System and the Law of the Sea, LeidenBoston, Martinus Nijhoff, 2005.

KLabbers, Jan, “Treaties, Object and Purpose”, enWolfrum, Rüdiger (ed.), The Max Planck Encyclopedia of Public International Law, Oxford, Oxford University Press, 2012.

KLEIn, Natalie, Dispute Settlement in the UN Convention on the Law of the Sea, Cambridge, Cambridge University Press, 2004.

KLInE, Robert T., "The Pen and the Sword:The People's Republic of China's Effort to Redefine the Exclusive Economic Zone Through Maritime Law Fare and Military Enforcement”, Military Law Review, vol. 216, 2013.

KNIGHT, H. Gary, "The Potential Use of Reservations to International Agreements Produced by the Third United Nations Conference on the Law of the Sea", Policy Issues in Ocean Law, Studies in Transnational Legal Policy, American Society of International Law, 1975, núm. 8.

Kohona, Palitha T. B., "Some Notable Developments in the Practice of the UN Secretary-General as Depositary of Multilateral Treaties: Reservations and Declarations", American Journal of International Law, vol. 99, núm. 2, 2005. 
Esta revista forma parte del acervo de la Biblioteca Jurídica Virtual del Instituto de Investigaciones Jurídicas de la UNAM

Moncayo, Guillermo R. et al., Derecho internacional público, 3a. reimp., Buenos Aires, Zavalía, 1990, t. I.

Naime S. Henkel, Monica Y., "El final de la espiral del caos: la regulación de los actos jurídicos unilaterales de los Estados", Anuario Mexicano de Derecho Internacional, vol. XII, 2012.

NelSON, L. Dolliver M., "Declarations, Statements and «Disguised Reservations» with Respect to the Convention on the Law of the Sea", The International and Comparative Law Quarterly, vol. 50, núm. 4, 2001.

OXMAN, Bernard H., "The Third United Nations Conference on the Law of the Sea: The Ninth Session (1980)", American Journal of International Law, vol. 75, núm. 2, 1981.

Pedrozo, Raul, "Preserving Navigational Rights and Freedoms: The Right to Conduct Military Activities in China's Exclusive Economic Zone", Chinese Journal of International Law, vol. 9, núm. 1, 2010.

PeLleT, Alain, "The ILC Guide to Practice on Reservations to Treaties: A General Presentation by the Special Rapporteur", The European Journal of International Law, vol. 24, núm. 4, 2013.

Rodríguez Cedeño, Víctor y Torres Cazorla, María Isabel, "Nullity, Revocation, and Revision of Unilateral Acts", en WOLFRUM, Rüdiger (ed.), The Max Planck Encyclopedia of Public International Law, Oxford, Oxford University Press, 2012.

Romano, Cesare, "The Southern Bluefin Tuna Dispute: Hints of a World to Come... Like It or Not", Ocean Development \& International Law, núm. 32, 2001

WalKer, George K., 'Professionals' Definitions and States' Interpretative Declarations (Understandings, Statements, or Declarations) for the 1982 Law of the Sea Convention”, Emory International Law Review, vol. 21, 2007. Wood, Michael, "Institutional Aspects of the Guide to Practice on Reservations", The European Journal of International Law, vol. 24, núm. 4, 2013. YaO-Dong, Yu y Wen-Jin, Piao, "Legal Study on Military Activities in the EEZ: With a Focus on Foreign Military Activities in the EEZ of P. R. China”, KMI International Journal of Maritime Affairs and Fisheries, núm. 3, 2011.

Jurisprudencia (en orden cronológico y según su sistema de cita oficial)

Case of the S. S. "Wimbledon”, P.CIJ, Judgment of 17 August 1923 (Serie A, núm. 1). 
Esta revista forma parte del acervo de la Biblioteca Jurídica Virtual del Instituto de Investigaciones Jurídicas de la UNAM

Nationality Decrees in Tunis and Morocco, P.CIJ, Advisory Opinion of 7 February 1923 (Serie B, núm. 4).

Question of Jaworzina (Polish-Czechoslovakian Frontier), P.CIJ, Judgment of December 6th, 1923 (Serie B, núm. 8).

Interpretation of Judgments Nos. 7 and 8 (Factory at Chorzów), P.CIJ, Judgment of December 16th, 1927 (Serie A, núm. 13).

Access to, or anchorage in, the Port of Danzig, of Polish war vessels, P.CIJ, Advisory Opinion of 11 December 1931 (Serie A/B, núm. 43).

Interpretation of Peace Treaties (second phase), Advisory Opinion, ICJ Reports 1950. Request for Interpretation of the Judgment of November 20th, 1950, in the asylum case, Judgment of November 27th, 1950, ICJ Reports 1950.

Nuclear Tests (New Zealand v. France), Judgment, ICJ Reports 1974.

Nuclear Tests (Australia v. France), Judgment, ICJ Reports 1974.

Aegean Sea Continental Shelf, Judgment, ICJ Reports 1978.

Frontier Dispute, Judgment, ICJ Reports 1986.

Fisheries Jurisdiction (Spain v. Canada), Jurisdiction of the Court, Judgment, ICJ Reports 1998.

CORTE IDH, Caso Hilaire vs. Trinidad y Tobago. Excepciones preliminares. Sentencia del 1o. de septiembre de 2001 (Serie C, núm. 80).

Armed Activities on the Territory of the Congo (New Application: 2002) (Democratic Republic of the Congo v. Rwanda), Jurisdiction and Admissibility, Judgment, ICJ Reports 2006.

Maritime Delimitation in the Black Sea (Romania v. Ukraine), Judgment, ICJ Reports 2009.

The ARA Libertad Arbitration (Argentina v. Ghana), Notice of Arbitration, 29 October 2012.

"ARA Libertad"Case (Argentina v. Ghana), ITLOS, Provisional Measures, Order of 15 December 2012.

The ARA Libertad Arbitration (Argentina v. Ghana), Agreement between Argentina and Ghana, 27 September 2013.

The Arctic Sunrise Case (Kingdom of the Netherlands v. Russian Federation), ITLOS, Provisional Measures, Order of 22 November 2013.

The Arctic Sunrise Arbitration (Netherlands v. Russia), Award on Jurisdiction dated 26 November 2014.

The South China Sea Arbitration (The Republic of Philippines v. The People's Republic of China), Award of 12 July 2016. 